\title{
DISCIPLINA JURÍDICA DO INSIDER TRADING: O CRITÉRIO DA RELEVÂNCIA DA INFORMAÇÃO
}

\author{
DISSERTAÇÃO DE MESTRADO \\ Orientador: Professor Associado Dr. Eduardo Secchi Munhoz
}

UNIVERSIDADE DE SÃO PAULO

FACULDADE DE DIREITO

SÃO PAULO - SP

JANEIRO DE 2018 

Alex S. Hatanaka

\title{
DISCIPLINA JURÍDICA DO INSIDER TRADING: O CRITÉRIO DA RELEVÂNCIA DA INFORMAÇÃO
}

\begin{abstract}
Dissertação apresentada à Banca Examinadora do Programa de Pós-Graduação em Direito, da Faculdade de Direito da Universidade de São Paulo, como exigência parcial para obtenção de título de Mestre em Direito, na área de concentração de Direito Comercial, sob a orientação do Professor Associado Dr. EDUARDO SECCHI MUNHOZ.
\end{abstract}

\section{UNIVERSIDADE DE SÃO PAULO}

\section{FACULDADE DE DIREITO}

São Paulo/SP

Janeiro de 2018 


\section{Catalogação da Publicação \\ Serviço de Biblioteca e Documentação \\ Faculdade de Direito da Universidade de São Paulo}

Hatanaka, Alex S.

Disciplina Jurídica do Insider Trading: O Critério da Relevância da

Informação / Alex S. Hatanaka ; orientador Eduardo Secchi Munhoz -- São

Paulo, 2018. 223 p.

Dissertação (Mestrado - Programa de Pós-Graduação em Direito

Comercial) Faculdade de Direito, Universidade de São Paulo, 2018

1. Mercado de Capitais. 2. Insider Trading. 3. Informação Privilegiada. 4. Critério da Relevância. 5. Teoria do Mosaico. I. Munhoz, Eduardo Secchi, orient. II. Título. 
Candidato: AleX S. HATANAKA

Título: Disciplina jurídica do insider trading: o critério da relevância da informação

Dissertação apresentada à Faculdade de Direito da Universidade de São Paulo, como exigência parcial para a obtenção de título de Mestre em Direito

Banca Examinadora

Prof. Dr.

Julgamento:

Prof. Dr.

Julgamento:

Prof. Dr.

Julgamento:
Instituição:

Assinatura:

Instituição:

Assinatura:

Instituição:

Assinatura: 
Para Karin, Arthur e Elisa 


\section{AGRADECIMENTOS}

Antes de mais nada, agradeço à minha família. A minha esposa e companheira, Karin, pelo carinho, convívio, amor e, sobretudo, a compreensão com as longas horas de dedicação a este estudo. A meus filhos, Arthur e Elisa, por trazerem alegria e inspiração diária. A meus pais, Lilia e Riosuque, e meus irmãos, Alan e Analy, por sempre poder contar com o carinho e suporte e por sempre apoiarem os meus estudos.

Em particular, gostaria de expressar a minha imensa gratidão ao Professor Eduardo Secchi Munhoz, pelo incentivo para o meu retorno às cadeiras acadêmicas, pela firme orientação ao longo desta pesquisa e, por fim, e não menos importante, por propiciar a minha primeira oportunidade na área jurídica, na forma de um estágio no então chamado Lilla, Huck, Malheiros, Otranto, Ribeiro, Camargo e Messina Advogados, que, de modo definitivo, alterou o rumo da minha carreira.

Registro, ainda, meu agradecimento aos Professores Francisco Satiro de Souza Jr. e Evandro Fernandes de Pontes, pelas excelentes críticas e sugestões pertinentes feitas no exame de qualificação. Aos professores Eduardo Secchi Munhoz, José Alexandre Tavares Guerreiro, Francisco Satiro de Souza Jr., Paulo Fernando Campos Salles de Toledo, Mauro Rodrigues Penteado, Rachel Sztajn, Haroldo Malheiros Duclerc Verçosa, Marcos Paulo de Almeida Salles, Carlos Alberto Carmona e Giovanni Bonato, o meu obrigado pela condução das marcantes matérias que pude cursar e que, em muito, contribuíram para meu desenvolvimento acadêmico e profissional.

A todos aqueles que, direta ou indiretamente, contribuíram para a conclusão deste trabalho, gostaria de registrar o meu agradecimento. Agradecimentos, em particular, a Daniela M. L. Sanchez Andrei, Francisco P. de Crescenzo Marino, Flavio Okamoto, Cristiano de Sousa Zanetti, John William Anderson Jr., Guilherme Favaro Ribas, Rogerio Taffarello, Marcela Venturini Diorio, Dora Cavalcanti, Estela Paro Ali Matos, Letícia Rocha Gouveia, Sarah R. F. Rotta, Rhaiza G. Peres Ceolim, Paula de Souza Gonçalves e Carlos A. J. de Andrade Garcia, por comentários, ajuda com materiais e pesquisa ou, simplesmente, incentivo, todos importantes para o resultado final. Ao professor Renato Vilela, registro meu agradecimento por ter generosamente dividido a pesquisa que alicerçou a preparação de seu 
livro Insider trading: normas, instituições e mecanismos de combate no Brasil. São Paulo: FGV Direito SP, 2016.

Sou imensamente grato à Faculdade de Direito da Universidade de São Paulo, a velha e sempre nova Academia do Largo de São Francisco, que ajudou a moldar quem sou, e também à Escola de Administração de Empresas de São Paulo da Fundação Getulio Vargas, que me assegurou conhecimentos que extrapolam o âmbito jurídico.

Um caloroso agradecimento, também, a meus sócios e colegas do escritório Mattos Filho, Veiga Filho, Marrey Jr. e Quiroga Advogados, que me permitiram balancear a vida profissional com a acadêmica. Um agradecimento também aos colegas de trabalho do Bank of America Merrill Lynch, Goldman Sachs e Machado, Meyer, Sendacz e Opice, que me ajudaram a chegar até aqui.

Por fim, cabe destacar que as opiniões expressadas neste trabalho, assim como suas imperfeições, são de responsabilidade exclusiva do autor e não devem ser interpretadas como a opinião de qualquer instituição a que o autor esteve ou esteja vinculado, tampouco das pessoas aqui antes referidas. 
Hatanaka, Alex S. Disciplina jurídica do insider trading: o critério da relevância da informação. 2018. 223 págs. Dissertação (Mestrado). Faculdade de Direito da Universidade de São Paulo, São Paulo, 2018.

\section{RESUMO}

O presente estudo se volta a examinar criticamente a disciplina jurídica da vedação ao uso indevido de informação privilegiada (insider trading), com particular ênfase ao exame do critério de relevância da informação. A matéria encontra-se em voga, como se percebe da atuação intensa da CVM em casos relacionados a essa conduta e pelas recentes mudanças drásticas legislativas em matéria de processos administrativos sancionadores e no tipo penal do uso indevido de informação privilegiada. Para esse propósito, a evolução do mercado de capitais brasileiro e as correspondentes alterações legislativas serão brevemente visitadas, para, na sequência, serem abordados os diversos fundamentos que justificam e impõem que a legislação das sociedades anônimas e do mercado de capitais prevejam a ilicitude do insider trading e imponha penalidades àqueles que violem as disposições legais em questão. Essa análise sugere que a legislação evoluiu do seu objetivo original de proteger a companhia aberta de eventual violação dos deveres de lealdade e sigilo dos administradores para encampar o princípio do acesso paritário às informações relevantes, hoje dominante na maioria dos países à exceção dos EUA. Após propor uma definição de uso indevido de informação privilegiada e identificar os requisitos para a sua configuração, o critério da relevância da informação será analisado em seus múltiplos aspectos e desdobramentos. Em particular, será abordada a licitude, de acordo com o ordenamento brasileiro, do uso da chamada teoria do mosaico, segundo a qual um investidor capacitado pode conjugar informações não relevantes e não divulgadas, dados públicos e informações por ele desenvolvidas, formando um mosaico do qual é potencialmente possível extrair conclusões relevantes. Essas atividades de análise são parte crucial do papel desempenhado por investidores profissionais, gestores e analistas de valores mobiliários, que, a seu turno, são essenciais para a disseminação de informação analítica de alta qualidade para o mercado e para a promoção da liquidez e a formação precisa de preço.

Palavras-chave: Mercado de Capitais; Insider Trading; Informação Privilegiada; Critério de Relevância; e Teoria do Mosaico. 
HATANAKA, Alex S. Legal regime of insider trading: materiality threshold of the information. 2018. 223 pages Master of Laws Dissertation, Faculty of Law, University of São Paulo, São Paulo, 2018.

\begin{abstract}
This study is devoted to critically review the legal regime applicable to the prohibition to insider trading, with particular focus on the materiality threshold of the information. The subjet matter is currently in the spolight, as one can conclude from the intense efforts by the CVM staff in connection with this offense and also the recent drastic legislative changes to the administrative enforcement system and to the criminal offense definition. With that purpose in mind, we will briefly touch upon the history of the Brazilian capital markets and the corresponding legislative landscape and, thereafter, will analyze the principles and objetives that and make it necessary for the Brazilian Corporation and Securities Law to render insider trading illegal and impose penalties on those that breach such legal provision. The analysis suggests that the original legislative purpose of protecting the corporations against potential breach of fiduciary duties has evolved to protect the parity of access to material information, which is the prevailing principle in most of the countries other than the U.S.. After proposing a definition for insider trading and identifying the requirements for a case to be presented in court, we will analyze the materiality threshold of the information and its multiple angles and consequences. In particular, we will review the lawfulness under Brazilian laws and regulations of the use of the so-called mosaic theory, whereby a skillful investor can piece together non-relevant, non-public information, public data and information developed by the investor, forming a mosaic that enables the investor to potentially draw material conclusions. Such analysis activities are a crucial part of the role played by professional investors, managers and research analysts, who, in turn, are an essential part of the securities market and are key for the dissemination of high quality analysis information to the market and promotion of liquidity and accurate price formation of the securities.
\end{abstract}

Keywords: Capital Markets; Insider Trading; Inside Information; Materiality Threshold; and Mosaic Theory. 
1. MERCADO DE CAPITAIS E A EVOLUÇÃO LEGISLATIVA ................................ 12

1.1. Período anterior à Lei da Reforma Bancária ....................................................... 12

1.2. A Lei da Reforma Bancária e leis correlatas .......................................................... 12

1.3. A Lei do Mercado de Capitais, o milagre brasileiro e o encilhamento de 1971 .... 13

1.4. Lei das S/A e Lei do Mercado de Valores Mobiliários ........................................... 18

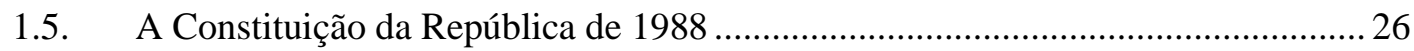

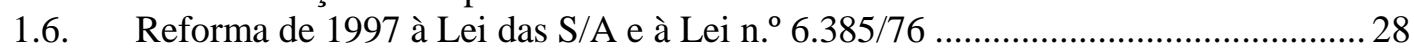

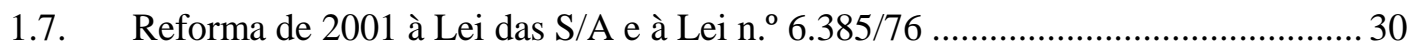

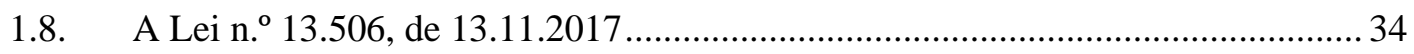

1.9. O mercado de capitais atual e a segurança jurídica ............................................. 35

2. FUNDAMENTOS DA VEDAÇÃO AO INSIDER TRADING .....................................39

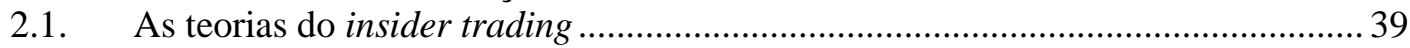

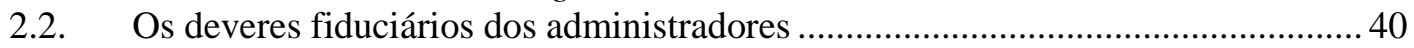

2.2.1. O dever de lealdade na Lei das S/A............................................................ 40

2.2.2. Fiduciary duties nos EUA e as decisões em Chiarella e Dirks ................... 43

2.2.3. A teoria do misappropriation e os casos Carpenter e O'Hagan ................... 45

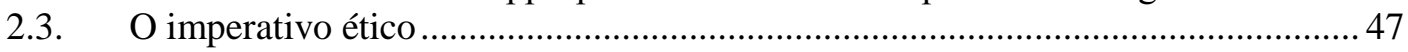

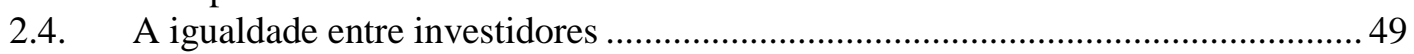

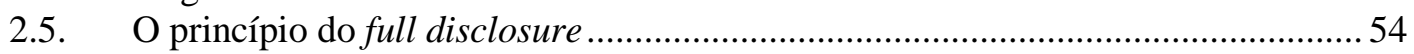

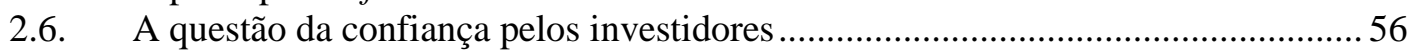

2.7. O princípio da boa-fé nas negociações e o dever de informar..................................6 60

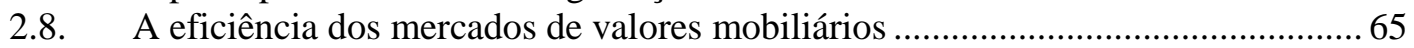

2.8.1. Hipótese do Mercado Eficiente e as ideias de Henry Manne .................... 65

2.8.2. Críticas à tese de Henry Manne sob a ótica de Direito e Economia ........... 68

2.8.3. Crítica das Finanças Comportamentais ...................................................... 70

2.8.4. Busca pelo mercado eficiente no Brasil .................................................. 71

2.9. O argumento de perdas e danos das contrapartes .................................................. 73

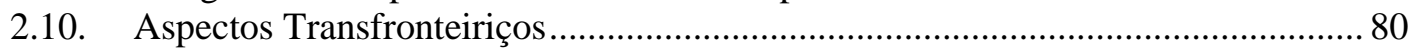

2.11. Fundamentos da vedação no Brasil ....................................................................... 86

3. USO INDEVIDO DA INFORMAÇÃO PRIVILEGIADA _......................................... 89

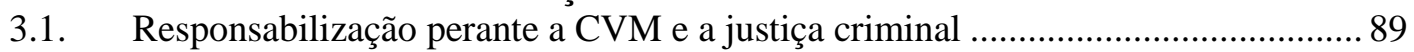

3.2. Requisitos para a configuração do ilícito na responsabilização administrativa ..... 92

3.2.1. Legislação e normas regulamentares .................................................. 92

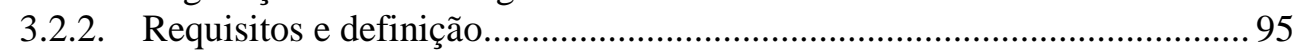

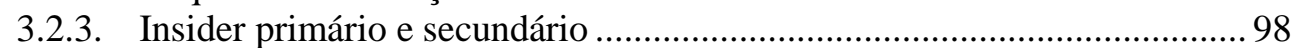

3.2.4. Conhecimento da informação privilegiada ............................................. 106

3.2.5. Uso da informação em negociação com valores mobiliários ................... 107

3.2.6. Elemento Subjetivo ............................................................................ 113

3.2.7. Informação privilegiada.................................................................... 115

3.3. Questões probatórias na responsabilização administrativa ................................. 115

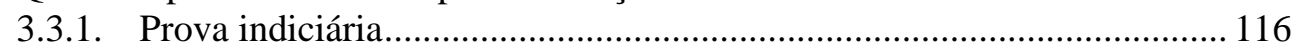

3.3.2. Presunção relativa da Instrução CVM n. ${ }^{0} 358 / 2002$...................................... 118

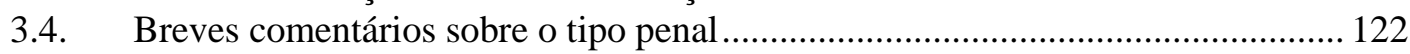

3.4.1. Bem jurídico protegido ......................................................................... 122

3.4.2. Sujeitos ativo e passivo dos tipos ............................................................. 123

3.4.3. Tipo objetivo do caput: adequação típica do uso indevido de informação

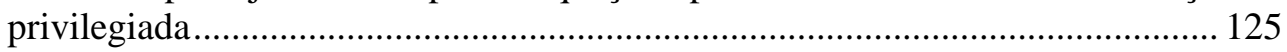

3.4.4. Tipo objetivo do $§ 1 .^{\circ}:$ adequação típica do repasse de informação privilegiada. 


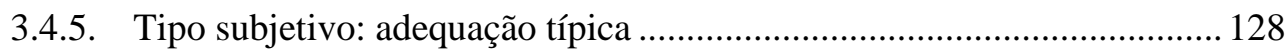

4. INFORMAÇÃO PRIVILEGIADA E O CRITÉRIO DA RELEVÂNCIA ......................130

4.1. Conceito e conteúdo da informação privilegiada ............................................... 130

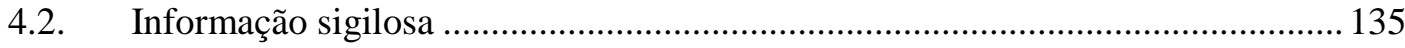

4.3. O critério da relevância da informação............................................................. 140

4.3.1. Contexto legal e regulamentar ................................................................. 140

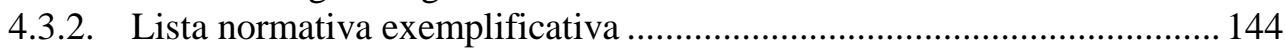

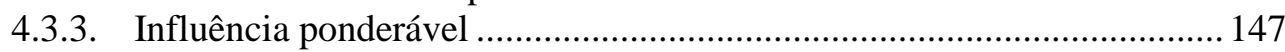

4.3.4. Poder de influir sobre a cotação e sobre a decisão dos investidores......... 148

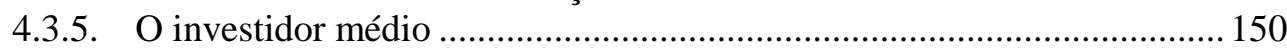

4.3.6. Alteração da cotação após a divulgação ................................................ 159

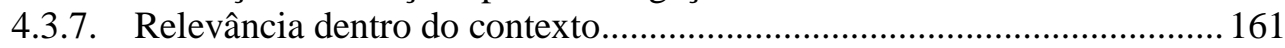

4.3.8. Distinção entre informação relevante e fato relevante............................... 162

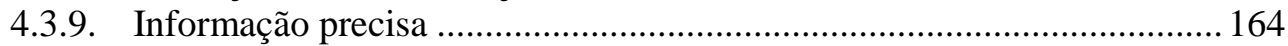

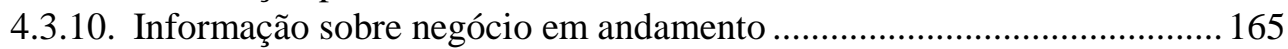

4.3.11. Absorção pelo mercado e perda de relevância............................................ 166

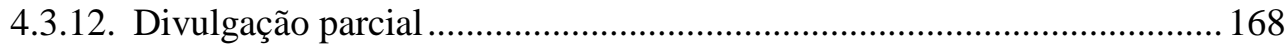

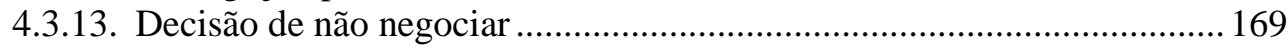

4.3.14. Regras específicas adicionais para ofertas públicas de distribuição e de

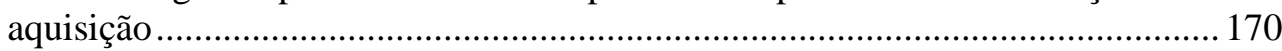

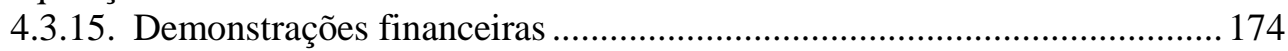

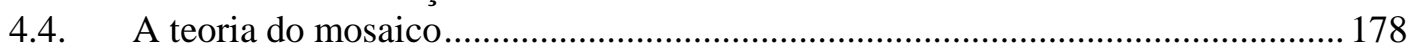

4.4.1. A origem da teoria do mosaico nos EUA ............................................ 178

4.4.2. Análise da sua aplicação no sistema regulatório brasileiro ........................ 189

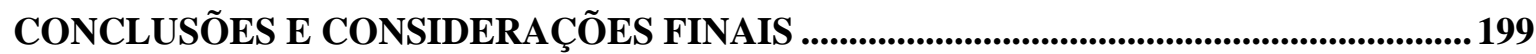

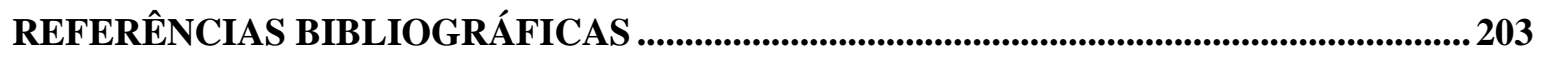

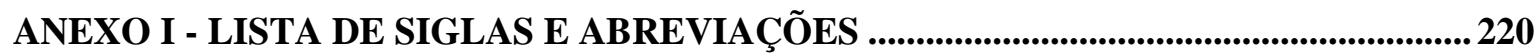

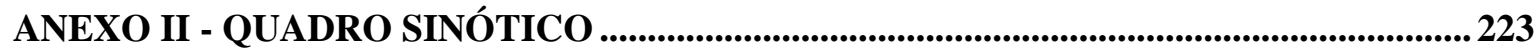




\title{
INTRODUÇÃO
}

\author{
"Price is what you pay, value is what you get" (Warren Buffett). \\ "I contend that financial markets never reflect the underlying reality \\ accurately; they always distort it in some way or another and the \\ distortions find expression in market prices" (George Soros). \\ "You have to talk to company management, look into their eyes, and \\ determine whether they are reliable" (Mark Mobius) \\ "Investing without research is like playing stud poker and never \\ looking at the cards" (Peter Lynch).
}

Cada uma das citações acima, todas de ícones do mercado financeiro, revela um núcleo comum à mente dos investidores de sucesso. No plano concreto, não há mercado de valores mobiliários totalmente eficiente ou informação puramente completa e, justamente por isso, o valor real de um ativo nem sempre está refletido no preço de mercado. Os agentes que operam também estão longe de ser o homem econômico infalível. Navegando com habilidade por essas águas, com o objetivo de identificar esses desalinhamentos, é que os investidores de sucesso conseguem auferir ganhos.

E é importante que se diga, desde o limiar da análise, que há maneiras absolutamente lícitas de se obter informações para identificar os ativos cujos valores intrínsecos não estão refletidos em seus preços de mercado.

O investidor pode estudar a fundo uma dada companhia, seus dados financeiros, o mercado em que se insere, seus competidores, clientes e fornecedores, dedicar-se com afinco a obter informações sobre os mais diversos aspectos de seus negócios, discutir com especialistas no setor de atuação de tal empresa, contratar relatórios emitidos por analistas de valores mobiliários que cubram a empresa emissora, empregar profissionais altamente capacitados em avaliação de investimentos e, mediante o uso de todo esse ferramental, em seu conjunto, tomar uma decisão informada e racional de investimento.

Nesse cenário, o investidor está buscando tomar uma decisão com base em um conjunto informacional superior ao restante do mercado, criando uma assimetria 
informacional, para poder fazer um investimento potencialmente mais promissor. É o que de melhor fazem Warren Buffett, George Soros, Peter Lynch ${ }^{1}$ e tantos outros investidores renomados.

Com o objetivo de identificar essas oportunidades, os investidores recorrem a diversos recursos informacionais ou serviços especializados e, em muitos casos, regulados. Podem, por exemplo, se valer de relatórios preparados por analistas de valores mobiliários (os chamados research analysts) ${ }^{2}$, de avaliação de agências de classificação de risco (rating) ou de diversas outras fontes de informação de negócios, como Bloomberg, Reuters, jornais, revistas e outros serviços de inteligência. Podem, outrossim, utilizar os serviços de consultores de valores mobiliários ${ }^{3}$ para auxiliá-los no processo decisório. Em certos casos, podem até mesmo fazer um processo de seleção criteriosa voltado a contratar um gestor ${ }^{4}$ para gerir sua carteira de recursos - ou parte dela - de modo discricionário e especializado. Além disso, podem preparar estudos comparativos com competidores, análises de cenários macroeconômicos ou políticos, visitar presencialmente a companhia e concorrentes, pesquisar a opinião de consumidores, fornecedores e especialistas no setor em questão e conduzir a sua própria investigação. Enfim, tudo isso para conseguir um diferencial informacional e para auxiliá-los a pinçar as boas oportunidades do mercado ${ }^{5}$.

\footnotetext{
${ }^{1}$ Peter Lynch é um investidor norte-americano famoso por seu papel de gestor do Fidelity Magellan Fund (Fidelity Investments), entre 1977 a 1990, período em que o patrimônio líquido do fundo aumentou de U.S.\$18 milhões para U.S.\$14 bilhões.

${ }^{2}$ Segundo a Instrução CVM n. ${ }^{\circ}$ 483, de 06.07.2010, conforme alterada, analista de valores mobiliários é a "pessoa natural que, em caráter profissional, elabora relatórios de análise destinados à publicação, divulgação ou distribuição a terceiros, ainda que restrita a clientes" (art. 1. ${ }^{\circ}$ ). Os relatórios de análise são "textos, relatórios de acompanhamento, estudos ou análises sobre valores mobiliários específicos ou sobre emissores de valores mobiliários determinados que possam auxiliar ou influenciar investidores no processo de tomada de decisão de investimento" (art. $\left.1^{\circ}{ }^{\circ}, \S 1^{\circ}{ }^{\circ}\right)$, sendo que são equiparadas a relatórios "exposições públicas, apresentações, reuniões, conferências telefônicas e quaisquer outras manifestações não-escritas, cujo conteúdo seja típico de relatório de análise" (art. 1. $\left.{ }^{\circ}, \S 2 . .^{\circ}\right)$.

${ }^{3}$ Nos termos do art. 1. ${ }^{\circ}$ da Instrução CVM n. ${ }^{\circ}$ 592, de 17.11.2017, “[c]onsidera-se consultoria de valores mobiliários a prestação dos serviços de orientação, recomendação e aconselhamento, de forma profissional, independente e individualizada, sobre investimentos no mercado de valores mobiliários, cuja adoção e implementação sejam exclusivas do cliente".

${ }^{4}$ A gestão de recursos é categoria de registro de administrador de carteira de valores mobiliários que pode ser requerida à CVM de acordo com o inciso II do $§ 1 .^{\circ}$ do art. $1 .^{\circ}$ da Instrução CVM n. ${ }^{\circ} 558$, de 26.03.2015, conforme alterada. A administração de carteira, que é mais abrangente, é assim definida no art. $1 .^{\circ}$ de tal norma regulamentar: "[a] administração de carteiras de valores mobiliários é o exercício profissional de atividades relacionadas, direta ou indiretamente, ao funcionamento, à manutenção e à gestão de uma carteira de valores mobiliários, incluindo a aplicação de recursos financeiros no mercado de valores mobiliários por conta do investidor".

${ }^{5} \mathrm{O}$ uso dessa caixa de ferramentas é não só comum, como recomendado, para investidores institucionais como fundos de pensão, seguradoras, asset managers, gestores de fortunas e muitos dos investidores não
} 
Em um exemplo oposto, mas singelo, um investidor de má índole poderia, simplesmente, cooptar um membro do conselho de administração de uma companhia aberta, para lhe fornecer informações a respeito dos negócios antes da sua divulgação ao mercado. Pior ainda, remunerá-lo para confidenciar fatos sensíveis. Com isso, tal investidor deterá, evidentemente, informações que revelam que a cotação de mercado de valores mobiliários de tal companhia se descolou de seu valor real. Essa ação é claramente ilícita e merece censura ${ }^{6}$.

A legislação e regulamentação preconizam que as informações que preencham o critério de relevância devem ser de conhecimento de todos aqueles que estão negociando no mercado de valores mobiliários, ou seja, há uma planificação obrigatória, sem a possibilidade de divulgação seletiva. Trata-se do chamado market egalitarianism. Abaixo da linha da relevância encontra-se o espectro de atuação em que os investidores, analistas, gestores e outros profissionais de mercado podem legitimamente se diferenciar, estudando a fundo a situação da companhia e embasando sua análise de riscos e, portanto, decisões de investimento.

Assim, traçar essa linha entre o que é relevante e o que não é se mostra um esforço de inegável utilidade, pois demarca a fronteira entre duas situações bastante distintas.

Na primeira hipótese, em que está configurada a relevância, o detentor da informação (usualmente, os administradores) tem a obrigação de publicizar a informação relevante por meio de anúncio de fato relevante ou, se houver uma razão legítima, poderá mantê-la em sigilo, mas, no último caso, se abstendo de negociar com valores mobiliários. Ou seja, disclose or abstain from trading, para usar a feliz expressão cunhada no caso Cady, Roberts que será abordado.

Já na segunda hipótese, não há a necessidade de publicar as informações, por não atingirem o patamar da relevância, nem deve haver restrições à negociação em valores

residentes que aplicam recursos no mercado de valores mobiliários em benefício de terceiros, perante os quais terminam por ter deveres fiduciários, devendo, assim, empregarem todas as suas habilidades e diligência para assegurar o melhor retorno possível.

${ }^{6}$ E é muito similar, por exemplo, ao que fez Raj Rajaratnam, fundador do fundo Galleon International, ao obter informações privilegiadas de uma ampla rede de contatos de insiders. Por todos, veja-se o caso das informações fornecidas por Rajat K. Gupta, conforme comunicado do U.S. Attorney for the Southern District, disponível em: <https://www.justice.gov/archive/usao/nys/pressreleases/June12/guptarajatverdict.html> (acessado em 08.01.2018). 
mobiliários pelos insiders e, tampouco, é necessário a priori impedir que a administração da companhia discuta algumas dessas informações com investidores e profissionais de mercado no interesse da companhia.

Na segunda situação, ainda, as informações não relevantes que forem divididas com investidores e outros agentes podem ser por eles utilizadas, em conjunto com as informações públicas ou informações por eles desenvolvidas, podendo chegar a conclusões potencialmente relevantes, por meio da organização do quebra-cabeça de informações que se forma em seu estudo. Essa análise do conjunto de informações recebe proteção nos EUA sob a égide da teoria do mosaico, que, a todo sentir, deve receber proteção entre nós também, como se verá.

Ainda do lado dos investidores, a melhor definição dessa linha se tornou particularmente importante, em virtude do movimento legislativo de aproximar o modelo brasileiro de repressão ao insider trading ao sistema europeu, abraçando de modo mais claro uma abordagem lastreada na igualdade do acesso a informações relevantes, do que é sintomática a recente alteração implementada pela Lei n. ${ }^{\circ} 13.506 / 2017$ ao tipo penal do art. 27-D da Lei n. ${ }^{\circ}$ 6.385, de 07.12.1976, ou Lei do Mercado de Valores Mobiliários.

O modelo norte-americano, fonte de inspiração para a legislação e regulamentação do mercado de capitais brasileiro, vem sofrendo críticas contundentes pela inconsistência da evolução jurisprudencial e regulamentação do insider trading, que resultou em um foco excessivo na necessidade da violação de dever fiduciário para a caracterização do ilícito.

Por aqui, importa, cada vez menos, a análise de se a detenção da informação guarda algum nexo com o dever de lealdade societário de manter reserva do que ocorre no íntimo da companhia. A questão crucial é se o investidor, mesmo ciente de que a informação era relevante e não pública, ainda assim a usou com o (des)propósito de obter vantagem em negócios com valores mobiliários, não importando a forma pela qual a obteve.

Do lado das companhias abertas, a administração, em tarefa nada fácil, deve calibrar bem seu julgamento para determinar se divulga ou não um anúncio de fato relevante, aplicando à situação concreta o critério de relevância, em avaliação eminentemente subjetiva. E ainda que seja relevante, poderá decidir não publicar, desde que julgue estar diante de um interesse legítimo da companhia, outro conceito subjetivo. 
Como a não divulgação de ato ou fato relevante pode levar a responsabilização, por violação ao dever de informar encartado no art. $157, \S 4^{\circ}$, da Lei das S/A, há o risco da adoção de uma postura conservadora com a divulgação de toda e qualquer informação que tenha o potencial de ser relevante, cenário contraproducente e de divulgação excessiva ${ }^{7}$.

De um modo mais amplo, não há dúvida da pertinência de se discutir o tema do uso indevido de informação privilegiada, insider trading ou, ainda, como preferem os europeus, abuso de informação privilegiada. Há tempos que o debate vem atraindo crescente atenção, com ampla cobertura midiática ${ }^{8}$. A questão, aliás, exerce até mesmo um certo fascínio no público em geral, muito em razão da ideia de que o uso de informação privilegiada pode propiciar enriquecimento em patamares astronômicos, imagem que é fomentada até mesmo pela própria indústria cinematográfica.

Nos EUA, a partir dos anos 80, a capacidade de investigação e enforcement da SEC e do DOJ mudou absolutamente de patamar. Entre tantos outros casos ruidosos, basta citar a prisão, em 2004, da celebridade Martha Stewart ${ }^{9}$, em caso que se tornou verdadeira obsessão midiática e era referido como um caso de insider trading, embora tecnicamente a base de sua persecução tenha sido perjúrio.

Outro caso amplamente coberto nos veículos de comunicação envolveu o bilionário Raj Rajaratnam, fundador do hedge fund Galleon Group, e uma ampla rede de tippees, que incluía o ex-CEO da consultoria McKinsey \& Co., Rajat Gupta. Por fim, insta recordar o vistoso acordo celebrado em 2013 pela SEC, DOJ e o hedge fund SAC Capital Advisors LP, no astronômico valor de U.S.\$ 1,8 bilhão, para encerrar processos relativos a insider trading ${ }^{10}$.

\footnotetext{
${ }^{7}$ Vide, a respeito, PAREDES, Troy A. Blinded by the Light: Information Overload and its Consequences for Securities Regulation. In: Washington Law Quarterly, vol. 81, n. ${ }^{\circ}$ 2, 2003, pp. 417-86.

${ }^{8}$ No campo do jornalismo, a obra Den of Thieves. Simon \& Schuster, 1992, de autoria do jornalista James B. Stewart, vencedor do prêmio Pulitzer, narrou diversos episódios de insider trading, manipulação de mercado e fraude no mercado de capitais norte-americano ao longo dos anos 80, capitaneados por Ivan Boesky, Michael Milken, Martin Siegel, Dennis Levine e outros.

${ }^{9}$ Sobre o caso, veja HofFMAn, Drew. Martha Stewart's Insider Trading Case. In: Georgetown Journal of Legal Ethics, vol. 20, n. 3 (verão de 2007), pp. 707-718; e HEMINWAY, Joan MacLeod. Save Martha Stewart - Observations about equal justice in U.S. Insider Trading Regulation. In: Texas Journal of Women and the Law, vol. 12, n. 2 (primavera de 2003), pp. 247-286.

${ }^{10}$ Cf. Morrison \& FOERSTER LLP. Insider Trading: Annual Review 2013. Publicado em 2014. pp. 2-4 (disponível em <http://media.mofo.com/files/Uploads/Images/140108-Insider-Trading-Annual-Review.pdf>, acessado em 08.01.2018).
} 
Mas a SEC e DOJ não tiveram só vitórias nos últimos anos. No final de 2013, Mark Cuban, o famoso bilionário, atual dono do time de basquete Dallas Mavericks, venceu um julgamento decidido por júri, em ação proposta pela SEC por uso de informação privilegiada na venda de ações de uma empresa de internet para evitar perdas ${ }^{11}$. Em adição, uma polêmica decisão recente do Segundo Circuito da Justiça Federal determinou que, em casos de transmissão de informações privilegiadas, a acusação tem de demonstrar que aquele que transmite a informação (tipper) recebe um benefício efetivo daquele que a recebe e utiliza no mercado de valores mobiliários ${ }^{12}$.

No Brasil, a questão igualmente está em voga. Como os números demonstram, a CVM vem se mostrando mais presente e ativa na investigação e persecução administrativa, com crescente número de instauração de processos administrativos sancionadores, de condenações e de celebração de termos de compromisso. A crescente atuação da autarquia fica evidente da leitura de pesquisas empíricas conduzidas nos últimos anos ${ }^{13}$.

Convém salientar que a autarquia firmou, em 2008, um Termo de Cooperação Técnica com o Ministério Público Federal, buscando se integrar de forma mais entranhada no sistema de enforcement e aproximar-se para trocar informações e atuar conjuntamente na prevenção e combate às práticas lesivas ao mercado de valores mobiliários ${ }^{14}$. Em linha similar, o órgão regulador divulgou que, em 2014, deu início ao uso de uma ferramenta de monitoramento eletrônico para a fiscalização do mercado de capitais ${ }^{15}$.

${ }^{11}$ Brody, Sarah; ThOMPSOn, Carol Lynn; e SPENCER-MorK, Nathaniel. District Court Dismisses Insider Trading Complaint Against Mark Cuban. In: Financial Fraud Law Report. Outubro de 2009. Disponível em https://www.sidley.com/-/media/files/publications/2009/10/district-court-dismisses-insider-tradingcomplai_/files/view-article/fileattachment/financialfraudlawreport1009.pdf (acessado em 08.01.2018)

${ }^{12}$ United States v. Newman, 773 F. 3d 438 (2d Cir. 2014), cert. denied, 136 S. Ct. 242 (2015). Comentando o precedente e seus efeitos, vale conferir a análise de EPSTEIN, Richard A. Returning to Common-Law Principles of Insider Trading after United States v. Newman. In: Yale Law Journal, vol. 125, n. ${ }^{\circ} 5$ (março de 2016), pp. 1482-1530.

${ }^{13}$ Vide, a respeito, (a) PRADO, Viviane Muller (coord.). Insider Trading: dados e reflexões. Cadernos Direito GV. Seminário 38, vol. 7, n. 6, pp. 57-62, novembro 2010; (b) PRADO, Viviane Muller; e VILELA, Renato. "Radiografia de insider trading na CVM". Núcleo de estudos em Mercados e Investimentos - Direito GV, 2014 (disponível em <http://media.wix.com/ugd/66710c_e1b69e3f3f6843b092456f8551464531.pdf>, acessado em 08.01.2018); e (c) PRADO, Viviane Muller; RACHMAN, Nora; e VILELA, Renato. Insider trading: normas, instituições e mecanismos de combate no Brasil. São Paulo: FGV Direito SP, 2016.

14 Termo de Cooperação Técnica disponível no link http://www.cvm.gov.br/export/sites/cvm/noticias/ anexos/2013/20130508-1-termo-de-cooperacao-cvm-mpf.pdf (acessado em 08.01.2018).

${ }^{15} \mathrm{O}$ contrato entre CVM e SIA S.p.A., com objeto na disponibilização, manutenção e suporte do sistema SIA-EAGLE, foi firmado em 27.01.2014 (Disponível em <http://www.cvm.gov.br/export/sites/ cvm/licitacao/contrato/anexos/2014/ct06/1.-CT-6_2014.pdf >, acessado em 08.01.2018) e tal contratação e uso foi divulgada em jornais e revistas. 
Não bastasse isso, em 01.06.2016, a BM\&FBOVESPA promoveu o lançamento do Guia de Combate ao Insider Trading, formulado pelo chamado GT Interagentes, que congregou representantes de diversas associações e entidades de mercado ${ }^{16}$. Na mesma ocasião, a CVM lançou o seu Caderno Educativo sobre o "Uso indevido de informação privilegiada (insider trading)" ${ }^{\prime 17}$, com o objetivo de promover a cultura do combate ao insider trading e elevar o nível de informação disponível no mercado sobre a questão.

Em particular, o então presidente da CVM, Leonardo Pereira ressaltava que o combate ao insider trading é uma das prioridades da CVM, destacando que "combater o uso de informação privilegiada é uma das questões chave para o mercado brasileiro atualmente e uma preocupação significativa para nós. Acreditamos fortemente que um mercado de capitais saudável não pode coexistir com o insider trading e informações assimétricas, uma vez que trazem incerteza e falta de confiança para os investidores"18.

Convém recordar, no ponto, que a CVM se tornou, aos poucos, o palco da resolução de disputas a que investidores recorrem no âmbito do mercado de capitais ${ }^{19}$. Não diferentemente, em relação ao insider trading, o que se vê é uma concentração da discussão na seara administrativa, já que dificuldades estruturais impedem uma maior efetividade repressiva na persecução penal, assim como a busca de reparação no âmbito civil por eventuais prejudicados. Daí que se decidiu por uma abordagem do tema primordialmente sob a ótica da persecução no âmbito administrativo.

Outra evidência patente da atualidade do tema é a recente efervescência legislativa em torno da questão, como mostra a vinda da Medida Provisória n. ${ }^{\circ}$ 784, de 07.06.2017,

${ }^{16}$ Participaram da iniciativa as associações ABRAPP, ABRASCA, ABVCAP, AMEC, ANBIMA e APIMEC, além da BM\&FBOVESPA, BRAiN, IBGC, IBMEC e o IBRI

17 “Uso Indevido de Informação Privilegiada (Insider Trading)". Comissão de Valores Mobiliários. Rio de Janeiro: Comissão de Valores Mobiliários, 2016. 45p. (Cadernos CVM, 11).

18 "Fighting against the use of privileged information is one of the Brazilian market key issues today and a significant concern for us. We strongly believe that a healthy capital market cannot coexist with insider trading and asymmetric information, once it brings uncertainty and lack of confidence to investors" (Discurso na 39 a Conferência Anual da IOSCO de 2014 no Rio de Janeiro, disponível em <https://www.iosco.org/library/annual_conferences/pdf/39/DiscursoIOSCO2014.pdf>, acessado em 08.01.2018, nossa tradução).

${ }^{19}$ ARAgão, Paulo Cezar. "A CVM em juízo: limites e possibilidades". In: Revista de Direito Bancário e do Mercado de Capitais, v. 9, n. 34. São Paulo: RT, pp. 38-49, out./dez. 2006, p. 41. Em sentido similar, Nelson Eizirik e Aurélio Wander Bastos já afirmavam que a aplicação dos dispositivos legais e regulamentares versando sobre insider trading pela CVM era satisfatória e uniforme, o mesmo não se podia verificar na órbita do Poder Judiciário (O Poder Judiciário e a Jurisprudência sobre Sociedades Anônimas e Instituições Financeiras. Rio de Janeiro: IBMEC, 1980, pp. 12-8). 
tratando de processos administrativos sancionadores no âmbito da CVM e do Banco Central do Brasil, e da Lei Federal n. ${ }^{\circ}$ 13.506, de 13.11.2017, que substituiu a medida provisória após sua perda de vigência e, inter alia, promoveu a já aludida expansão do tipo penal previsto no art. 27-D da Lei do Mercado de Valores Mobiliários.

Em linha com o que ocorre nos EUA, a imprensa local tem dado ampla cobertura a casos de insider trading. Basta verificar as inúmeras notícias a respeito do caso de executivos da Sadia e do ABN-AMRO que negociaram ADRs da Perdigão na NYSE, no período em que a primeira discutia e se preparava para formular oferta hostil pelo controle da segunda. Tal caso originou, além do processo administrativo sancionador na CVM, persecução nos EUA promovida pela SEC e, no âmbito judiciário, resultou na primeira condenação penal, confirmada em segundo grau e no Superior Tribunal de Justiça, sob a égide do tipo penal previsto no art. 27-D da Lei n. ${ }^{\circ} 6.385 / 76$ em sua redação original.

Na seara acadêmica, há, nos EUA, farto material doutrinário sobre diversos aspectos da questão, além de uma quantidade substancial de precedentes judiciais que foram moldando o conceito de insider trading por lá, uma vez que não há, em lei, uma definição específica do ilícito, mas, tão-somente, uma regra antifraude.

No Brasil, em sede doutrinária, o professor Luiz Gastão Paes de Barros Leães ${ }^{20}$ foi o pioneiro a tratar do assunto na obra clássica "Mercado de capitais e insider trading", publicada há mais de 35 anos. José Marcelo Martins Proença ${ }^{21}$ também abordou a questão com maestria em "Insider trading: regime jurídico do uso de informações privilegiadas no mercado de capitais", há mais de uma década. Em 2017, o advogado Francisco Antunes Maciel Müssnich publicou também livro dedicado ao tema, "Insider trading no Direito Brasileiro" 22 , analisando diversos precedentes da CVM e dando particular ênfase às discussões de estruturas de barreiras de informação (chinese walls) em conglomerados financeiros e à aplicabilidade da teoria do domínio do fato a casos de insider trading.

\footnotetext{
${ }^{20}$ LEÃES, Luiz Gastão Paes de Barros. Mercado de Capitais e Insider Trading. São Paulo: RT, 1982.

21 ProEnçA, José Marcelo Martins. Insider Trading: Regime Jurídico do Uso de Informações Privilegiadas no Mercado de Capitais. São Paulo: Quartier Latin, 2005.

${ }_{22}^{2}$ MÜSSNICH, Francisco Antunes Maciel. O insider trading no Direito Brasileiro. São Paulo: Saraiva, 2017, baseado em sua dissertação de 2015, de mesmo título, apresentada à Escola de Direito da Fundação Getúlio Vargas do Rio de Janeiro como requisito para a obtenção de título de mestre em Direito da Regulação.
} 
Na academia, nesta Faculdade de Direito da Universidade de São Paulo, em 2007, Thiago A. Spercel defendeu dissertação de mestrado, sob a orientação do professor Haroldo Malheiros Duclerc Verçosa, com o título "Mercado de capitais e insider trading” $\mathrm{e}$ recentemente, em 2016, Silvia Labriola Cavalieri Fittipaldi defendeu dissertação de mestrado, sob a orientação do professor Carlos Pagano Botana Portugal Gouvêa, intitulada "A repressão ao insider trading no Brasil: panorama atual e novas perspectivas", ambos trabalhos de inegável qualidade.

Sem querer repetir o que já foi examinado com maestria, a presente dissertação tem como objetivo delinear um ponto mais específico da problemática do insider trading, qual seja o critério da relevância que qualifica a informação como privilegiada. Embora aspectos da responsabilização penal e da ação de indenização sejam abordados ao longo do texto, o estudo se concentrará na atuação administrativa da CVM no âmbito das companhias $\operatorname{abertas}^{23}$.

A propósito, a expressão insider trading ${ }^{24}$, embora oriunda da língua inglesa, será utilizada ao longo do estudo, em razão de sua ampla consolidação na literatura científica internacional e a sua utilização firme entre nós também ${ }^{25}$. Na Inglaterra e Europa, disseminou-se a expressão insider dealing, mas o termo não recebeu a mesma acolhida no Brasil. Desde logo, assim, pede-se a devida licença e o correspondente perdão, pela farta utilização de palavras em língua estrangeira ao longo da dissertação.

\footnotetext{
${ }^{23}$ Nelson Eizirik sustenta que a proibição ao insider trading é aplicável tanto às negociações realizadas no mercado (em Bolsa de Valores ou no Mercado de Balcão) quanto às negociações privadas, assim entendidas aquelas realizadas sem a interveniência de instituição financeira integrante do sistema de distribuição de valores mobiliários, nas chamadas operações face to face praticadas pelo insider (Cf. EIZIRIK, Nelson. A Instrução CVM 31/84 e a regulamentação do Insider trading. In: Revista de Direito Mercantil, Industrial, Econômico e Financeiro, vol. 23, n. ${ }^{\circ}$ 55, pp. 170-75, jul./set. 1984, p. 173).

${ }^{24}$ Fabio Konder Comparato bem explica que insider trading ou insider dealing são expressões que ainda não receberam uma tradução consagrada para a língua portuguesa (A regra do sigilo nas ofertas públicas de aquisição de ações. In: Direito Empresarial: Estudos e Pareceres. $1^{\mathrm{a}}$ ed., $2^{\mathrm{a}}$ tiragem, São Paulo: Saraiva, pp. 331-353, 1995, p. 338)

${ }^{25}$ Basta lembrar o uso da expressão nos títulos das principais obras publicadas sobre o assunto, e.g, Luiz Gastão Paes de Barros Leães. Mercado de Capitais e Insider Trading. São Paulo: RT, 1982; José Marcelo Martins Proença. Insider Trading: Regime Jurídico do Uso de Informações Privilegiadas no Mercado de Capitais. São Paulo: Quartier Latin, 2005; e Francisco Antunes Maciel Müssnich. $O$ insider trading no Direito Brasileiro. São Paulo: Saraiva, 2017 (grifou-se). Na Europa, utiliza-se os termos "abuso de informação privilegiada" para a conduta de insider trading, "iniciado" para insider e "recomendar ou induzir" é usado para tipping, mas houve pouca adesão no Brasil.
} 
Ainda sobre a expressão, é importante esclarecer que, apesar da ampla acolhida, é um termo que contém uma grave imprecisão cuja extensão convém aclarar. O insider trading (i.e., literalmente, a negociação por aquele que está por dentro) nem sempre é ilegal. Em sua versão lícita e regular, os insiders - conselheiros, diretores e colaboradores - negociam valores de tais companhias, fora de períodos sobre os quais recaiam restrições e fazem a apropriada divulgação de tais negócios ao mercado.

Nesse exercício, todavia, há que se lembrar que a aplicação de teorias estrangeiras à realidade brasileira sempre há de ser feita com a devida cautela. $\mathrm{O}$ cenário brasileiro é, predominantemente, de empresas com capital concentrado na mão de acionistas controladores, de modo que o conflito mais intenso nas companhias brasileiras tende a ser entre os acionistas controladores e não controladores e não entre os administradores e os acionistas. No ponto, interessantíssima a reflexão de Calixto Salomão Filho de que " $a$ relação controlador-minoritário gera uma assimetria de informação natural, de difícil disciplina pelo direito societário (...) A diferença de informação entre os insiders da companhia (controladores e administradores) e os outsiders (minoritários e investidores) é imensa"26. Em outras palavras, quer parecer possível inferir que a estrutura corporativa brasileira potencializa o campo de oportunidades para insider trading.

Outro ponto importante na transposição das teorias relativas a insider trading ao Brasil é que os padrões culturais e valores predominantes no Brasil são conducentes a comportamentos do controlador com o objetivo de extrair benefícios privados do controle ${ }^{27}$,

${ }^{26}$ Informação completa, Direito Societário e mercado de capitais. In: O Novo Direito Societário. $4^{\mathrm{a}}{ }^{\mathrm{ed}}$., revista e ampliada, São Paulo: Malheiros Editores, pp. 177-187, 2015, p. 184-5. Em sentido similar, sustenta Érica Gorga que "o nível eficiente de prestação de informações no Brasil é diferente, por exemplo, do nível eficiente nos Estados Unidos, em razão das discrepâncias entre custos e benefícios marginais existentes em cada mercado. Desse modo, cada agente regulador deve observar e analisar as características específicas de cada mercado para determinar qual informação deve ser revelada e a melhor maneira de fazê-lo" (Direito Societário Atual. Rio de Janeiro: Elsevier, 2013, p. 87).

27 Ver, a respeito, a análise dos fatores de desenvolvimento do mercado de capitais apresentada por Eduardo Secchi Munhoz (Aquisição de Controle na Sociedade Anônima. Saraiva: São Paulo, 2013, p. 71-100), remetendo aos tempos de Brasil colonial, que culminam em um cenário de companhias em que o controlador se considera o "dono" da empresa, ao passo que os investidores são vistos como instrumentos para a realização dos projetos do empresário-empreendedor. No mesmo sentido, Erica Gorga (Op. Cit., 2013, p.70-4 e em A cultura brasileira como fator determinante na governança corporativa e no desenvolvimento do mercado de capitais". In: Revista de Administração, São Paulo, vol. 39, n. . 4, p. 309-26, 2004, p. 314-5). Ambos autores fazem referência ao estudo de Alexander Dyck e Luigi Zingales, que, após analisar 39 países, conclui que, no Brasil, em operações de transferência de controle havidas entre 1990 e 2000, os benefícios privados extraídos pelo acionista controlador eram os maiores na amostra, gerando um prêmio de controle da ordem de $65 \%$, em comparação com 14\% de média na amostra (DYCK, Alexander; e ZINGALES, Luigi. Private Benefits of Control: An International Comparison. In: The Journal of Finance, vol. LIX, No. 2, pp. 537-600, abril de 2004, p. 538). 
mesmo porque a história brasileira leva a uma situação em que o controlador se vê como o dono da empresa e os investidores como instrumentos de viabilização de seu projeto.

Feitos esses esclarecimentos metodológicos e de escopo, a essa altura vale tratar como o estudo se organizará. Como se sabe, a interpretação de uma norma não pode se restringir à análise de sua letra fria, impondo-se ao exegeta um aprofundamento teleológico, sistêmico, social e histórico.

Daí que, antes de adentrar o objeto deste estudo propriamente dito, o Capítulo I versará, em primeiro lugar, sobre a evolução legislativa e regulamentar até os dias atuais e, segundo, sobre aspectos chave do desenvolvimento do mercado de capitais brasileiro. A seu turno, o Capítulo II se debruçará sobre os fundamentos e objetivos que fundamentam, condicionam e justificam a vedação ao uso indevido de informação privilegiada. O Capítulo III analisará os requisitos do insider trading para a responsabilização sob a persecução administrativa e algumas ponderações sobre o tipo penal. O Capítulo IV abordará a definição de informação privilegiada, o critério da relevância da informação e a teoria do mosaico. Por fim, serão tecidas algumas considerações finais em vista da análise empreendida. 


\section{CONCLUSÕES E CONSIDERAÇÕES FINAIS}

O efetivo combate ao uso indevido de informação privilegiada é medida que se impõe em prestígio à igualdade de acesso informacional (market egalitarianism), ao correto e eficiente funcionamento do mercado de valores mobiliários e à preservação da confiança dos investidores.

No palco da repressão ao insider trading, a CVM vem assumindo um protagonismo importante para o desenvolvimento do mercado de valores mobiliários. Seguindo os passos das autoridades norte-americanas, que, a partir da década de 90, levantaram, com convicção, a bandeira do combate ao insider trading, a CVM vem, de forma ostensiva, dispensando à repressão dessa conduta tratamento especial dentro de sua pauta.

A postura mais ativa do órgão regulador se beneficia da recente revisão da legislação que disciplina os processos administrativos sancionadores, concretizada com a vinda da Medida Provisória n. ${ }^{\circ}$ 784/2017, que perdeu sua eficácia por falta de cumprimento de prazo, mas foi ressuscitada na forma da Lei n. ${ }^{\circ}$ 13.506/2017, que tramitou com surpreendente urgência no Congresso Nacional, em vista do conturbado contexto ali instaurado à época. Com isso, os poderes sancionatórios da CVM foram reforçados pela vinda da novel legislação.

Vale lembrar que a criação da CVM e a legislação do mercado de capitais foram notoriamente inspiradas na experiência norte-americana, em particular pela adoção do regime de full disclosure e da regra, que o complementa, impondo que os administradores "disclose or abstain from trading".

Ocorre que, embora tenha sido o nascedouro do combate ao insider trading, os EUA tornaram-se uma exceção no mapa global, remanescendo como um dos poucos países que não adota legislação detalhada a respeito do tema de insider trading, escorando-se na norma geral antifraude no melhor estilo da Common Law. Como se viu, em virtude do enfoque dado pela Suprema Corte em Chiarella e Dirks, a repressão ao uso da informação privilegiada continua a se alicerçar na determinação se houve a violação de um dever fiduciário para a obtenção da informação privilegiada, enquanto, na maioria das outras 
jurisdições, a perspectiva passou a ser da busca de acesso paritário a informações relevantes ${ }^{549}$.

$\mathrm{Na}$ arquitetura da Lei das S/A e da Lei n. ${ }^{\circ}$ 6.385/76, nosso ordenamento concebeu o ilícito de uso indevido de informação privilegiada como uma conduta praticada, em regra, dentro da companhia aberta por aqueles que estavam dentro dela. A conduta afrontava o dever de lealdade. Um primeiro ajuste foi feito, mediante a aposição de um novo parágrafo na disposição legal sobre o dever de lealdade, amplificando a vedação para abranger “qualquer pessoa" que tenha tido acesso à informação privilegiada. A expansão foi notável, mas os laços com os deveres fiduciários inegavelmente permaneciam, mesmo porque a norma continuava dentro da Lei das S/A e, sobretudo, como parte da disposição a respeito do dever de lealdade. A corroborar, o tipo penal então criado fazia menção expressa a "dever

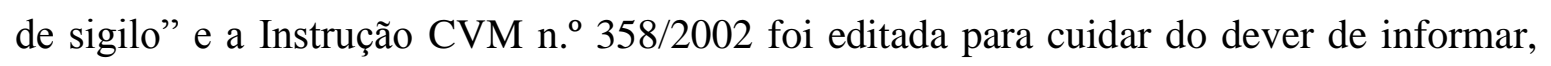
dever de sigilo e da vedação de negociar (insider trading), como um conjunto coeso e mutuamente complementar. A vinda da alteração do tipo penal previsto no art. 27-D da Lei n. ${ }^{\circ}$ 6.385/76, em novembro de 2017, para romper sua vinculação, antes obrigatória, ao dever de sigilo, abre o horizonte para uma busca de mercado de valores mobiliários em que há um acesso paritário a informações relevantes, com suporte legislativo.

Daí que não há dúvida de que o caminho trilhado pelo Brasil converge para a tendência que vem se estabeleceu globalmente e que se descola da abordagem norteamericana. Esse distanciamento, é importante advertir, impõe que a tradicional transposição de conceitos, ideias e modelos, adotados nos EUA, para o Brasil, se faça com cautela e com a devida reflexão a respeito de seu cabimento.

O crescente rigor na legislação que busca a efetivação dos deveres dos participantes do mercado de capitais vem acompanhada de uma igualmente crescente preocupação por investidores, emissoras, administradores e demais participantes no sentido de atuar e conduzir seus negócios adequadamente.

549 Opiniões de inegável autoridade recomendam a urgente revisão do sistema norte-americano para cobrir as lacunas e contradições que foram se estabelecendo e só fizeram maximizar as incertezas e a necessidade de longos e custos litigiosos, com resultado pouco previsível. O professor John Coffee, Jr., por exemplo, propõe que a SEC edite novas regras para cuidar desses pontos (Mapping the Future of Insider Trading Law: of Boundaries, Gaps and Strategies. In: Columbia Business Law Review, vol. 2013, n. ${ }^{\circ}$ 2, pp. 281-317, 2013, p. 304-7). Edward Greene e Olivia Schmid, a seu turno, defendem uma ampla revisão legislativa para assegurar o acolhimento do regime de paridade informacional sem, contudo, prejudicar as atividades de análise de valores mobiliários realizadas por investidores e analistas (Op. Cit., 2013, p. 426). 
Se, de um lado, é essencial que as condutas reprováveis não passem incólumes, de outro, a falta de certeza e segurança jurídica, por certo, só faz desencorajar o desenvolvimento do mercado de valores mobiliários, pois os investidores estrangeiros destinarão seus recursos a locais com uma estrutura jurídica mais estável e previsível e os poupadores locais preferirão outros produtos de investimento, mesmo que com menor retorno.

Alguns pontos importantes foram abordados ao longo do estudo e reclamam atenção com o propósito de eliminar ou mitigar as incertezas.

Uma primeira questão que se deu notícia é que as tendências internacionais apontam para a urgente necessidade de se revistar o arranjo legislativo, prevendo duas esferas de apenamento incidindo sobre uma mesma conduta, em vista dos recentes acontecimentos testemunhados na União Europeia, Itália e França na esteira do julgamento do caso Grand Stevens \& ors v. Italy pelo Tribunal Europeu de Direitos Humanos (vide item 3.1). A impossibilidade da convivência de dois sistemas de apenamento conduz a necessidade de uma escolha que, no Brasil, parece óbvia, haja vista a relativa dormência da persecução criminal e a ausência de especialização.

Um segundo ponto a merecer especial olhar é a prática do uso de prova indiciária. $\mathrm{O}$ agravamento das possíveis penas coloca sobre a CVM a responsabilidade de atuar de modo ponderado e proporcional, em especial ao avaliar quadros probatórios em que somente existam provas indiretas da conduta em questão. Os indícios devem ser múltiplos, veementes, convergentes e graves para qualificarem como prova indiciária ${ }^{550}$. Condenações equivocadas afrontariam não só o princípio da presunção da inocência, como descredibilizariam o órgão regulador e o próprio mercado de valores mobiliários. Espera-se que a CVM tenha a serenidade de conduzir e instruir com maestria o volume de processos administrativos sancionadores que decorrerá do esperado desenvolvimento do mercado de valores mobiliários, com maior atratividade, mais participantes e maior volume de negociações.

Sob esse ângulo, sobressai a importância dos diversos participantes do mercado de manterem políticas e procedimentos que se conformem à legislação e regulamentação e, demais disso, documentem o cumprimento em caso de potencial necessidade. A estrutura de 
ônus probatório permite a adoção de presunções relativas em certas hipóteses, de sorte que a posse a provas sobre a conduta passada pode ser essencial para a defesa dos interesses dos participantes do mercado.

O critério da relevância é, como se viu, "conceito cuja determinação jamais se poderá pretender precisa ou exaustiva" ${ }^{551}$. Desde o início do estudo, nunca houve a pretensão de se postar balizas fixas e claras para todas as situações, com a identificação de fórmulas fixas e objetivas. O que se buscou, ao longo do item 4.3, foi traçar as regras fundamentais para auxiliar o intérprete na árdua tarefa de definição se uma dada informação é relevante, tratando de diversas situações que propiciam dúvida.

E como foi aludido, o esforço nesse tocante é importante não só para efeitos de caracterização da informação privilegiada, mas também para distinguir as informações que devem ser divulgadas obrigatoriamente, pois relevantes, daquelas que, embora estejam sujeitas ao dever de reserva, podem ser divididas em certas circunstâncias que se alinhem com o interesse social.

$\mathrm{O}$ interesse social em fomentar um mercado ativo e liquido de seus valores mobiliários conduz à necessidade de compartilhamento de informações com investidores profissionais, gestores de recursos e analistas financeiros de um modo mais amplo, que exercem atividades essenciais para o funcionamento adequado e eficiente dos mercados de valores mobiliários.

Retorna-se, assim, às citações apostas no intróito deste estudo. Nunca é demais ressaltar a importância, para o bom funcionamento dos mercados de valores mobiliários, da busca eterna e contínua, desempenhada por todos os investidores profissionais, gestores, analistas e consultores, com o objetivo - como se viu, legítima - de congregar as melhores e mais precisas informações para identificar as oportunidades dos mercados. Impor sanções a essas atividades, equiparando-as a insider trading, somente contribuirá para o desprestígio e o retrocesso no mercado de valores mobiliários. 


\section{REFERÊNCIAS BIBLIOGRÁFICAS}

1. ADAMEK, Marcelo Vieira von. Responsabilidade civil dos administradores de S/A (e as ações correlatas). São Paulo, Saraiva, 2009.

2. AKERLOF, George. The Market for 'lemmons': quality uncertainty and the market mechanism. In: Quarterly Journal of Economics, vol. 84, issue 3, 1970.

3. AlONSO, Leonardo. Crimes contra o mercado de capitais. Dissertação de Mestrado sob a orientação do Professor Associado Renato de Mello Jorge Silveira, apresentada à Faculdade de Direito da Universidade de São Paulo, São Paulo, 2009, p. 132.

4. Alvarenga, Maria Isabel de Almeida. Adequação das funções legais da Comissão de Valores Mobiliários à realidade brasileira. In: Revista de Direito Mercantil, Industrial, Econômico e Financeiro, v. 36, n. 105, São Paulo: Malheiros, pp. 144-58, jan/mar 1997.

5. ARAGão, Paulo Cezar. A Lei das Sociedades Anônimas e os padrões contábeis internacionais (IFRS): uma convivência nem sempre harmônica. In: VENANCIO FILHO, Alberto; LOBO, Carlos Augusto da Silveira; e RosmAn, Luiz Alberto Colonna. Lei das S.A. em seus 40 anos. Rio de Janeiro: Forense, pp. 661-682, 2017. . "A CVM em juízo: limites e possibilidades". In: Revista de Direito Bancário e do Mercado de Capitais, v. 9, n. 34. São Paulo: RT, pp. 38-49, out./dez. 2006.

6. ARMOUR, John; BengtZen, Martin; e EnRIQUes, Lucas. Investor Choice in Global Securities Markets. July 2017, p. 57. Disponível em http://www.law.columbia.edu/sites/default/files/ microsites/capital-markets/armour-bengtzen-enriques-final.pdf (acessado em 08.01.2018).

7. Ausubel, Lawrence M. Insider Trading in a Rational Expectations Economy. In: The American Economic Review, vol. 80, pp. 1022-1041, 1990.

8. BAINBRIDGE, Stephen M. Insider trading law and policy. Concepts and Insights Series. New York: Foundation Press, 2014.

. Regulating insider trading in post-fiduciary duty era: equal access or property rights? In: BAINBRIDGE, Stephen M. (ed.). Research Handbook on Insider Trading. Cheltenham, UK: Edward Elgar Publishing, pp. 80-98, 2013.

The Insider Trading Prohibition: A Legal and Economic Enigma. In: Florida Law Review, vol. 38, pp. 35-68, inverno de 1986.

9. BARBERIS, Nicholas e THALER, Richard H. "A survey of behavioral finance". In: CONSTANTINIDES, G. M.; HARRIS, N. e STUlZ, R. (editores). Handbook of the Economics and Finance. Amsterdam: Elsevier, 2003, pp. 1.051-1.121. 
10. BARbosA, Marcelo. Algumas Notas sobre Insider Trading. In: Venancio FILHO, Alberto; LoBo, Carlos Augusto da Silveira; e Rosman, Luiz Alberto Colonna. Lei das S.A. em seus 40 anos. Rio de Janeiro: Forense, 2017, pp. 272-296.

11. Bastos, Celso Ribeiro; e Martins, Ives Gandra. Comentários à Constituição do Brasil: promulgada em 5 de outubro de 1988. São Paulo: Saraiva, 1990.

12. BENY, Laura N. "Do Insider Trading Laws Matter? Some Preliminary Comparative Evidence". In: American Law and Economics Review, vol. 7, n. ${ }^{\circ}$ 1, pp. 144-83, 2005. Disponível em: https://ssrn.com/abstract=623481 (acessado em 08.01.2018).

A Comparative Empirical Investigation of Agency and Market Theories of Insider Trading. John M. Olin Center for Law \& Economics. Paper \#04-004. University of Michigan Law School, 2004, p. 4-5. Disponível em https://repository.law.umich.edu/ law_econ_archive/art4/ (acessado em 08.01.2018).

13. Berle JR., Adolf A.; e MeAns, Gardiner. The Modern Corporation \& Private Property; with a new introduction by Murray L. Weidenbaum and Mark Jensen. Tenth printing. New Brunswick, New Jersey: Transaction Publishers, 2009.

14. Bhattacharya, Utpal; DaOuk, Hazem. "The World Price of Insider Trading". In: The Journal of Finance, v. LVII, n. ${ }^{\circ}$ 1, Fevereiro 2002, p. 75-108, 2002.

15. BitenCOURT, Cezar Roberto; e BREDA, Juliano. Crimes contra o Sistema Financeiro Nacional e contra o mercado de capitais. $3^{\text {a }}$ edição, São Paulo: Saraiva, 2014.

16. BONDI, Bradley J; e LOFCHIE, Steven D. "The law of insider trading: legal theories, common defenses and best practices for ensuring compliance". In: 8 NYU Journal of Law \& Business, Fall 2011, pp. 151 e ss.

17. Brandeis, Louis. Other People's Money. Reimpressão de 2009. Createspace. 1914.

18. BRUDNEY, Victor. Insiders, Outsiders, and Informational Advantages under the Federal Securities Laws. In: Harvard Law Review, vol. 93, n. ${ }^{2}$, pp. 322-376, dez. 1979.

19. BRUno, Aníbal. Direito Penal. vol.1 - Parte Geral, Rio de Janeiro: Forense, 1959.

20. CAmpos, Luiz Antonio de Sampaio. "Conselho de Administração e Diretoria - Deveres e Responsabilidades”. In: LAMY FILHO, Alfredo; e PEDREIRA, José Luiz Bulhões (coords.). Direito das Companhias. 2ª ed., atual. e ref. Rio de Janeiro: Forense, pp. 790-913, 2017.

21. CARlton, Dennis W. e Fischel, Daniel R. The Regulation of Insider Trading. In: Stanford Law Review, vol. 35, n. ${ }^{\circ}$ 5, pp. 857-896, maio 1983. 
22. CARNEY, William J. Signalling and Causation in Insider Trading. In: Catholic University Law Review, vol. 36, n. ${ }^{\circ}$ 4, pp. 863-898, verão 1987.

23. Carvalho, Ney. A saga do mercado de capitais no Brasil. São Paulo: Saint Paul Editora, 2014.

24. Carvalhosa, Modesto. Comentários à Lei de Sociedades Anônimas, $3^{\circ}$ volume, $6^{\mathrm{a}}$ edição, revista e atualizada, $3^{\mathrm{a}}$ tiragem, São Paulo: Saraiva, 2015.

Oferta Pública de Aquisição de Ações. Rio de Janeiro: IBMEC, 1979.

25. Carvalhosa, Modesto; e EIZIRIK, Nelson. A Nova Lei de S/A. São Paulo: Saraiva. 2002.

26. CASTEllaR, João Carlos. Insider Trading e os novos crimes corporativos. Rio de Janeiro: Lumen Juris, 2008.

27. CEREZETTI, Sheila Christina Neder. Regulação do mercado de capitais e desenvolvimento. In: SALOMÃo FILHO, Calixto (org.). Regulação e desenvolvimento. São Paulo: Malheiros, 2012, pp. 190-228.

28. CHEDIAK, Julian F. P. A reforma do mercado de valores mobiliários. In: LOBO, Jorge (coord.). Reforma da Lei das Sociedades Anônimas. Rio de Janeiro: Forense, 2002.

29. ChOI, Stephen J.; e PRITChARD, A. C. Behavioral Economics and the SEC. In: Stanford Law Review, vol. 56, n. ${ }^{\circ}$ 1, pp. 1-74 (outubro 2003).

30. CODORNIZ, Gabriela; e PATElla, Laura (coords.). Comentários à Lei do Mercado de Capitais - Lei . $^{\circ}$ 6.385/76. São Paulo: Quartier Latin, 2015.

31. COFFEE JR., John C. Mapping the Future of Insider Trading Law: of Boundaries, Gaps and Strategies. In: Columbia Business Law Review, vol. 2013, n. ${ }^{\circ}$ 2, pp. 281-317, 2013, p. 304-7. . "Competition Among Securities Markets: A Path Dependent Perspective" (março de 2002). Columbia Law and Economics Working Paper No. 192, pp. 16-26. Disponível em: https://ssrn.com/abstract=283822 (acessado em 08.01.2018).

The Rise of Dispersed Ownership: The Role of Law in the Separation of Ownership and Control. In: Yale Law Journal, vol. 111, n. 1 (outubro 2001), pp. 1-82.

32. COMissão de VAlores Mobiliários. Uso Indevido de Informação Privilegiada (Insider Trading). Cadernos CVM n. ${ }^{\circ}$ 11, Rio de Janeiro, 2016.

33. COMPARATO, Fabio Konder. "A regra do sigilo nas ofertas públicas de aquisição de ações". In: Direito Empresarial: Estudos e Pareceres. $1^{\mathrm{a}}$ ed., $2^{\mathrm{a}}$ tiragem, São Paulo: Saraiva, 1995, pp. 331-353. 
Insider Trading: sugestões para uma moralização do nosso mercado de capitais. In: Ensaios e Pareceres de Direito Empresarial. Rio de Janeiro: Forense, pp. 3-15, 1978.

Aspectos Jurídicos da Macro-empresa. São Paulo: Revista dos Tribunais, 1970.

34. Cordeiro, António Manuel da Rocha e Menezes. Da boa fé no Direito Civil. Coimbra: Almedina, 2015,

35. Costa, Helena Regina Lobo da; Alonso, Leonardo; e CoElHo, Marina Pinhão. Dos crimes contra o mercado de capitais. In: Revista Literária do Direito, vol 53, São Paulo, pp. 30-33, 02.08.2004.

36. CostA, José de Faria; e RAmos, Maria Elisabete. O crime de abuso de informação privilegiada (insider trading). Coimbra: Coimbra Editora, 2006.

37. Cox, James D. "Insider Trading and Contracting: A Critical Response to the Chicago School". In: 1986 Duke Law Journal, 1986, pp. 628-659.

38. CRIMMINS, Stephen J. Insider Trading: Where is the Line. In: Columbia Business Law Review, vol. 2013, n. ${ }^{\circ}$ 2, pp. 330-368 (2013).

39. DAmODARAN, Aswath. Investment Valuation: Tools and Techniques for Determining the Value of Any Asset. $3^{\text {rd }}$ Edition, Wiley, 2012.

40. DAVIDOVICH, Marcos. "A grande muralha e o conflito de interesses na common law". In: Revista de Direito Bancário e do Mercado de Capitais. v. 61, São Paulo: RT, pp. 15-44, jul./set. 2013.

41. De Sanctis, Fausto Martin. Punibilidade no Sistema Financeiro Nacional. Campinas: Millenium, 2003.

42. DemSETZ, Harold. The Structure of Corporate Ownership: Causes and Consequences, In: Journal of Law \& Economics, vol. 26, n. ${ }^{\circ}$ 2, pp. 375-390, junho 1983.

43. Dolgopolov, Stanislav. Insider Trading, Informed Trading, and Market Making: Liquidity of Securities Markets in the Zero-Sum Game. In: William \& Mary Business Law Review, vol. 3, n. ${ }^{\circ} 1$, pp. 1-57, 2012.

Risks and Hedges of Providing Liquidity in Complex Securities: The Impact of Insider Trading an Options Market Makers. In: Fordham Journal of Corporate \& Financial Law, vol. 15, n. $2,2010$. 
44. Dufour, Olivia. L'affaire Grande Stevens sonne la fin de la double répression des abus de marché. Comentário à decisão da Corte Européia de Direitos Humanos, j. 04.03.2014. Grande Stevens et al. v. Itália. Req. $\mathrm{n}^{\circ}$ 18640/10, 18647/10, 18663/10, 18668/10 et 18698/10. Petites affiches, 30.03.2014, $\mathrm{n}^{\circ} 86, \mathrm{p} .4$.

45. DyCK, Alexander; e ZINGales, Luigi. Private Benefits of Control: An International Comparison. In: The Journal of Finance, vol. LIX, No. 2, pp. 537-600, abril de 2004.

46. EASTERbrooK, Frank. Insider Trading as an Agency Problem. In: PrATt, John W. and ZeCKHAUSER, Richard J. (eds.). Principles and Agents: The Structure of Business. Boston: Harvard Business School Press, 1985, pp. 81-100. Insider Trading, Secret Agents, Evidentiary Privileges, and the Production of Information. In: Supreme Court Review, 1981, pp. 309-65.

47. Easterbrook, Frank e Fischel, Daniel R. The Economic Structure of Corporate Law. Cambridge, MA: Harvard University Press, 1996. e FISCHEL, Daniel R. "Mandatory Disclosure and the Protection of Investors". In: Virginia Law Review, v. 70, n. 4, Charlottesville: Virginia Law Review Association, maio 1984, pp. $669 \quad$ (disponível em http://chicagounbound.uchicago.edu/cgi/viewcontent.cgi?article=2176\&context=journal arti cles, acessado em 12.07.2016).

48. EDWARDS, Robert; MAgEE, John; e BASSETTI, W. H. C. Technical Analysis and Stock Trends. $10^{\mathrm{a}}$ ed., CRC Press, 2012.

49. EIZIRIK, Nelson. A Lei das S/A Comentada. vol. II, Artigos 121 a 188. São Paulo: Quartier Latin, 2011.

Reforma das S.A. e do Mercado de Capitais. $2^{\mathrm{a}}$ ed., Rio de Janeiro: Renovar, 1998.

Questões de Direito Societário e Mercado de Capitais. Rio de Janeiro: Forense, 1987.

A Instrução CVM 31/84 e a regulamentação do Insider trading. In: Revista de Direito Mercantil, Industrial, Econômico e Financeiro, vol. 23, n. ${ }^{\circ}$ 55, pp. 170-75, jul./set. 1984.

Insider trading e a responsabilidade de administrador de companhia aberta.

São Paulo: Revista de Direito Mercantil, Industrial, Econômico e Financeiro, vol. 50, pp. 4256, abr./jun. 1983. 
; e Bastos, Aurélio Wander. O Poder Judiciário e a Jurisprudência sobre Sociedades Anônimas e Instituições Financeiras. Rio de Janeiro: IBMEC, 1980.

50. EIZIRIK, Nelson; GaAl, Ariádna B.; PARente, Flávia; e Henriques, Marcus de Freitas. Mercado de Capitais - Regime Jurídico. $3^{\text {a }}$ Ed. Revista e Ampliada. Rio de Janeiro: Renovar, 2011.

51. EPSTEIN, Richard A. Returning to Common-Law Principles of Insider Trading after United States v. Newman. In: Yale Law Journal, vol. 125, n. 5 (março de 2016), pp. 1482-1530.

52. Fabian, Christoph. O dever de informar no Direito Civil. São Paulo, RT, 2002.

53. FADANELLI, Vinicius Krüger Chalub. Termo de compromisso em processo administrativo sancionador da Comissão de Valores Mobiliários (dissertação de Mestrado). Prof. Orientador José Alexandre Tavares Guerreiro, São Paulo: FDUSP, 2013.

54. FAMA, Eugene F. Efficient Capital Markets II. In: The Journal of Finance, vol. 46, n. o 5, 1991, pp. $1575-1617$.

. Efficient Capital Markets: A review of theory and empirical work. In: Journal of Finance, vol. 25, issue 2, Papers and Proceedings of the Twenty-Eighth Annual Meeting of the American Finance Association New York, N.Y., Dezembro 28-30 de 1969 (maio, 1970), pp. 384-417.

55. FERBER, David. The Case Against Insider Trading: A Response to Prof. Manne. In: Vanderbilt Law Review, vol. 23, n. ${ }^{\circ}$, pp. 621-626, abril 1970.

56. Ferrara, Ralph C.; NAgy, Donna M.; ThOMAs, Herbert; e KiM, Thomas J. Ferrara on Insider Trading and the Wall. Nova Iorque: Law Journal Press, 2006.

57. FERREIRA, Daniel. Sanções administrativas. São Paulo: Malheiros, 2001.

58. FISCHER, Philip. Common Stocks and Uncommon Returns and others writings. New Jersey: John Wiley \& Sons, Inc., 2003, p. 44.

59. FITTIPALDI, Silvia Labriola Cavalieri. A repressão ao insider trading no Brasil: panorama atual e novas perspectivas. Dissertação de mestrado sob orientação do professor Carlos Pagano Botana Portugal Gouvêa, apresentada à Faculdade de Direito da Universidade de São Paulo, São Paulo, 2016.

60. Fox, Merritt B. Retaining Mandatory Securities Disclosure: Why Issuer Choice is Not Investor Empowerment. In: Virginia Law Review, vol. 85, n. 7, pp. 1335-1420, outubro 1999.

61. Fragoso, Heleno Cláudio. Lições de Direito Penal - A Nova Parte Geral. 9a. ed., Rio de Janeiro: Forense, 1985, p. 152. 
62. FRANÇA, Erasmo Valladão Azevedo e Novaes. Alteração do controle direto e indireto. In: Castro, Rodrigo R. Monteiro de; e Azevedo, André N. de Moura (org.). Poder de controle e outros temas de direito societário e mercado de capitais. São Paulo: Quartier Latin, 2010.

FrAnÇA, Erasmo Valladão A. e N. Ainda o Conceito de Benefício Particular: Anotações ao Julgamento do Processo CVM n. ${ }^{\circ}$ RJ 2009/5811. In: Revista de Direito Mercantil 149/150, ano XLVII (Nova Série), pp. 293-322, jan/dez 2008.

63. FRIED, Jesse M. "Insider Abstention". In: Yale Law Journal, vol. 13, 2003, pp. 455-92 (disponível em <http://papers.ssrn.com/sol3/Papers.cfm?Abstract_id=330520〉, acessado em 12.07.2016).

64. GILSON, Ronald J.; e KRAAKMAN, Reinier H. The Mechanisms of Market Efficiency Twenty Years Later: The Hindsight Bias. Columbia Law and Economics Working Paper No. 240; Stanford Law and Economics Olin Working Paper No. 270; Harvard Law and Economics Disc. Paper No. 446, October 2003. Disponível em https://ssrn.com/abstract=462786 (acessado em 08.01.2018) The Mechanisms of market efficiency. In: 70 Va. L. Rev. 549-644 (1984).

65. Gorga, Érica. Direito Societário Atual. Rio de Janeiro: Elsevier, 2013. A cultura brasileira como fator determinante na governança corporativa e no desenvolvimento do mercado de capitais. In: Revista de Administração, São Paulo, vol. 39, n. ${ }^{\circ}$ 4, p. 309-26, 2004.

66. Gorman, Christopher M. Are Chinese Walls the Best Solution to the Problems of Insider Trading and Conflicts of Interest in Broker-Dealers. In: Fordham Journal of Corporate \& Financial Law, Vol. 9, Issue 2 (2004), pp. 475-500.

67. Goshen, Zohar e PARChOMOvSky, Gideon. The Essential Role of Securities Regulation. In: Duke Law Journal, vol. 55, pp. 711-782, 2006.

68. GRANDIS, Rodrigo de. Aspectos penais do uso de informação privilegiada (insider trading) no Direito Brasileiro. In: VILARDI, Celso Sanchez; PEREIRA, Flávia Rahal Bresser; e DIAS NETO, Theodomiro (coord). Direito Penal Econômico: crimes financeiros e correlatos. Série GVLaw. São Paulo: Saraiva, pp. 139-180, 2011, p. 156.

69. Greene, Edward; e Schmid, Olivia. Duty-Free Insider Trading. Symposium: The Past, Present, and Future of Insider Trading Law: A 50th Anniversary Re-Examination of Cady, Roberts and the Revolution it Began. In: 2013 Columbia Business Law Review, 2013, pp. 369428.

70. GT Interagentes. Guia Educativo de Prevenção ao Insider Trading, 2016. 
71. GuERreIro, José Alexandre Tavares. Sociedade Anônima: dos sistemas e modelos ao pragmatismo. In: In: CASTRO, Rodrigo R. Monteiro de; AZEVEDO, Luis André N. de Moura (coord.). Poder de Controle e Outros Temas de Direito Societário e Mercado de Capitais São Paulo: Quartier Latin, pp. 20-28, 2010, p. 20

Sobre o poder disciplinar da CVM. In: Revista de Direito Mercantil, Industrial, Econômico e Financeiro, vol. 43, p. 64-78, 1981.

72. HAFT, Robert J. The Effect of Insider Trading Rules on the Internal Efficiency of the Large Corporation. In: Michigan Law Review, Vol. 80, No. 5 (Apr., 1982), pp. 1051-1071.

73. HARRIS, Larry. Trading and Exchanges: Market Microstructure for Practitioners. Financial Management Association Survey and Synthesis Series. Oxford University Press, 2002.

74. HATANAKA, Alex S. Limites da confidencialidade na arbitragem envolvendo sociedades por ações de capital aberto. In: Revista de Direito das Sociedades e dos Valores Mobiliários, v. 3, p. 111-146, 2016.

. Apontamentos sobre a unificação de ofertas públicas de aquisição de ações.

In: Revista de Direito das Sociedades e dos Valores Mobiliários, v. 1, p. 165-216, 2015.

75. HEMINWAY, Joan MacLeod. Save Martha Stewart-Observations about equal justice in U.S. Insider Trading Regulation. In: Texas Journal of Women and the Law, vol. 12, n. 2 (primavera de 2003), pp. 247-286.

76. Henning, Peter J. Between Chiarella and Congress: A Guide to the Private Cause of Action for Insider Trading under the Federal Securities Laws. In: University of Kansas Law Review, vol. 39, n. ${ }^{\circ}$, pp. 1-58, outono 1990.

77. HofFMAN, Drew. Martha Stewart's Insider Trading Case. In: Georgetown Journal of Legal Ethics, vol. 20, n. 3 (verão de 2007), pp. 707-718.

78. HoRwICH, Allan. The Mosaic Theory of Materiality - Does the Illusion Have a Future?. In: Securities Regulation Law Journal, Forthcoming; Northwestern Law \& Econ Research Paper No. 14-05, May 13, 2015. Disponível em: https://ssrn.com/abstract=2397445 (acessado em 08.01.2018).

79. Huddart, Steven J.; Hughes, John S.; e BrunnermeIER, Markus K. "Disclosure Requirements and Stock Exchange Listing Choice in an International Context". In: Journal of Accounting and Economics, vol. 26, n. ${ }^{\circ}$ s 1-3, 1998. Disponível em: https://ssrn.com/abstract=146737 (acessado em 08.01.2018).

80. Hungria, Nelson. Comentários ao Código Penal. vol. I, tomo II, Rio de Janeiro: Forense, 1978. 
81. International Organization of Securities Commissions Organization (IOSCO). Relatório do Comitê de Mercados Emergentes da IOSCO: "Insider trading: how jurisdictions regulate it?" março de 2003, Disponível em https://www.iosco.org/library/pubdocs/pdf/IOSCOPD145.pdf (acessado em 08.01.2018).

82. Jensen, Michael C.; e MeCKLing, William H. Theory of the Firm: Managerial Behavior, Agency Costs and Ownership Structure. In: Journal of Financial Economics, vol. 3 (4), pp. 305-360, 1976.

83. JENSEN, Michael C. Some anomalous evidence regarding Market efficiency. In: Journal of Financial Economics, vol. 6, n. ${ }^{\circ}$ s 2/3, pp. 95-101, 1978.

84. Kahneman, Daniel. Attention and Effort. Englewood Cliffs, NJ: Prentice-Hall, 1973.

85. Kahneman, Daniel; e TVersky, Amos. "Prospect Theory: An Analysis of Decision Under Risk”. In: Econometrica, vol. 47 (2), pp. 263-291, março de 1979 (disponível em https://www.princeton.edu/ kahneman/docs/Publications/prospect_theory.pdf, acessado em 08.01.2018).

86. KARMEL, Roberta S. The relationship between mandatory disclosure and prohibition against insider trading: why a property rights theory of insider trading is untenable. In: 59 Brook. L. Rev. 149, 169-70, 1993.

87. KIM, Sung Hui. Insider trading as private corruption. In: UCLA Law Review, vol. 61, n. ${ }^{\circ} 4$ (maio de 2014), pp. 928-1009.

88. KingSbURy, Benedict; Krisch, Nico e SteWART, Richard B. "The Emergence of Global Administrative Law". In: Law and Contemporary Problems, vol. 68, números 3 e 4 (verão/outono 2005), pp. 15-62.

89. KoBI, D. Casey. Wall Street v. Main Street: The SEC's New Regulation FD and It's Impact on Market Participants. In: Indiana Law Journal, vol. 77, n. 3, pp. 551-614 (verão 2002).

90. KRAAKMAN, Reinier. The Legal Theory of Insider Trading Regulation in the United States. In: Hopt, Klaus J. and WyMEERSCH, Eddy (editores). European Insider Dealing. London: Butterworths, pp. 39-55, 1991.

91. KraAkman, Reinier; Armour, John; Davies, Paul; Enriques, Luca; Hansmann, Henry; HERTIG, Gerard; HoPT, Klaus; KANDA, Hideki; PARGENDLER, Mariana; RINGE, Wolf-Georg; and RocK, Edward. The anatomy of corporate law. 3rd edition. Oxford: Oxford University Press, 2017.

92. KRIPKE, Homer. Manne's Insider Trading Thesis and Other Failures of Conservative Economics. In: Cato Journal, vol. 4, n. ${ }^{\circ}$ 3, pp. 945-958, inverno de 1985. 
93. LA PORTA, Rafael; LOPEZ-DE-SILANES, Florencio; e SHLEIFER, Andrei. What Works in Securities Laws. In: The Journal of Finance, vol. 61, n. ${ }^{\circ}$, fevereiro de 2006, pp. 1-28. . Corporate Ownership Around the World. In: 54 (2) Journal of Finance, 1999, pp. 471-517.

94. LA PORTA, Rafael; LOPEZ-DE-SILANES, Florencio; SHLEIFER, Andrei, e VISHNY, Robert. Law and Finance. In: 106 Journal of Political Economy, 1998, pp. 1113-1155.

. Legal Determinants of External Finance. In: 52 Journal of Finance, 1997, pp.

$1131-1150$.

95. Lamy Filho, Alfredo e BulHões PedreIRA, José Luiz. A Lei das S.A., $2^{\mathrm{a}}$ ed., Rio de Janeiro: Renovar, 1996.

96. LangeVoort, Donald C. Reflections on Scienter (and the Securities Fraud Case against Martha Stewart that never happened). In: Lewis \& Clark Law Review, vol. 10, n. 1 (primavera 2006), pp. 1-18. Investment Analysts and the Law of Insider Trading. In: Virginia Law Review, vol. 76, n. ${ }^{\circ}$ 5, pp. 1023-1054, agosto 1990.

97. Lawson, Gary. The Ethics of Insider Trading. In: Harvard Journal of Law \& Public Policy,

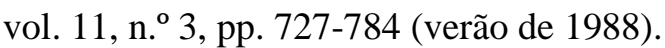

98. LEÃES, Luiz Gastão Paes de Barros. A adoção do Chinese Wall e a repressão ao insider trading. In: Revista de Direito Bancário e do Mercado de Capitais, vol. 47. São Paulo: RT, pp. 227-245, janeiro/março, 2010.

. Mercado de Capitais e Insider Trading. São Paulo: RT, 1982.

99. LeITE FILHO, José. Notas ao crime de uso indevido de informação privilegiada (art. 27-D da Lei 6.385/76). In: Revista Brasileira de Ciências Criminais, v. 14, n. 60, São Paulo: RT, pp. 78-117, maio 2006.

100. LORIA, Eli; e SILVA, Victor Hugo Cunha. Insider Trading e Provas Indiciárias na CVM: uma Análise Qualitativa e Quantitativa. In: Revista de Direito Bancário e do Mercado de Capitais, vol. 76, ano 20, pp. 289-314. São Paulo: RT, abr-jun 2017.

101. Loss, Louis. Fundamentals of Securities Regulation. 2a ed., Wolters Kluwer, 1988.

102. LuCEnA, José Waldecy. Das Sociedades Anônimas. Comentários à Lei. Vol. 2 (arts. 121 a 188). Rio de Janeiro: Renovar, 2009.

103. MACEY, Jonathan R. Insider trading - Economics, Politics and Policy. Washington DC: The AEI Press, 1991. 
104. Macey, Jonathan R. e Colombatto, Enrico. A Public Choice Model of International Economic Cooperation and the Decline of the Nation State. In: Cardozo Law Review, vol. 18, n. ${ }^{\circ} 3$ (dezembro 1996), pp. 925-956.

105. MACIEL, Karina Teresa da Silva; e MARTIn, Antonio. Efetividade da repressão ao insider trading. In: DARCANCHY, Mara Vidigal (org.). XXII Nacional Nacional Conpedi/Uninove. Santa Catarina: FUNJAB, v. 1, p. 300-325, 2013.

106. Manne, Henry G. The Collected Works of Henry G. Manne (General Editor: Fred S. McChesney). Volume 2 (Insider Trading). Indianapolis: Liberty Fund, 2009. Insider trading and property rights in new information. In: Cato Journal, vol. 4, n. ${ }^{\circ}$ 3, pp. 933-944, inverno 1985.

107. Marques, José Frederico. Elementos de Direito Processual Penal. Vol. 2, Campinas: Bookseller, 1998.

108. Martins, Fran. Comentários à Lei das S.A. vol. 2, tomo I, Rio de Janeiro, Forense, 1978.

109. Martins-Costa, Judith. A boa-fé no Direito Privado: critérios para a sua aplicação. São Paulo: Marcial Pons, 2015.

110. Mattos Filho, Ary Oswaldo; e SAntos, Mariana Magalhães. "O regime jurídico da informação privilegiada no Brasil”. In: Miranda, Jorge et al (comissão organizadora). Estudos em Homenagem a Miguel Galvão Teles. Vol. II, Coimbra: Almedina, 2012, pp. 619-35.

; e PRADO, Viviane Muller. "Tentativas de desenvolvimento do mercado acionário brasileiro desde 1964". In: Lima, Maria Lúcia L. M. Padua (coord.). Direito e Economia - 30 Anos de Brasil, tomo 2. Saraiva, pp. 191-215, 2012.

111. Medeiros, O. R.; e Matsumoto, A. S. Emissões Públicas de Ações, Volatilidade e Insider Information na Bovespa. In: Revista de Contabilidade e Finanças - USP, v. 40, janeiro/abril, 2006.

112. MedeIRos, Otavio Ribeiro de. Insider Trading in the Brazilian Stock Market. Publicado em 18.08.2009 (disponível em <http://ssrn.com/abstract=1457444〉 , acessado em 08.01.2018).

113. Mello, Rafael Munhoz de. Princípios Constitucionais de Direito Administrativo sancionador: as sanções administrativas à luz da Constituição Federal de 1988. São Paulo: Malheiros, 2007.

114. MENDELSON, Morris. The Economics of Insider Trading Reconsidered (Book Review). In:

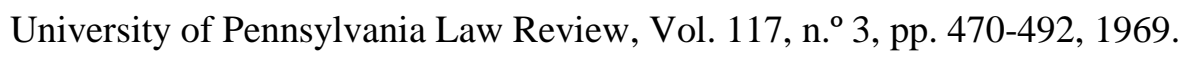


115. MeulbroeK, Lisa K. An Empirical Analysis of Illegal Insider Trading. In: The Journal of Finance, vol. 47, pp. 1661-99, 1992.

116. MORRISON \& FOERSTER LLP. Insider Trading: Annual Review 2013. Publicado em 2014. (disponível em <http://media.mofo.com/files/Uploads/Images/140108-Insider-TradingAnnual-Review.pdf>, acessado em 08.01.2018). . Insider trading annual review 2011, p. 2 (disponível em <http://media.mofo.com/files/Uploads/Images/2011-Insider-Trading-Review.pdf >, acessado em 08.01.2018).

117. MOSQUERA, Roberto Quiroga. “Os princípios informadores do direito do mercado financeiro e de capitais". In: MosQueRA, Roberto Quiroga (coord.). Aspectos Atuais do Direito do Mercado Financeiro e de Capitais, $1^{\circ}$ volume. São Paulo: Dialética, pp. 255-71, 1999.

118. MотA, Fernando de Andrade. $O$ dever de divulgar fato relevante na companhia aberta. São Paulo: Almedina, 2015.

119. MourA, Maria Thereza Rocha de Assis. A prova por indícios no processo penal. Rio de Janeiro: Lumen Juris, 2009.

120. MunHOZ, Eduardo Secchi. Influência do patrimonialismo na sociedade anônima - Importância dos mecanismos privados de efetivação dos devedores do acionista controlador e dos administradores. In: Venancio Filho, Alberto; Lobo, Carlos Augusto da Silveira; e Rosman, Luiz Alberto Colonna. Lei das S.A. em seus 40 anos. Rio de Janeiro: Forense, pp. 129-56, 2017.

Da alienação à aquisição de controle: uma nova interpretação para o art. 254-A da Lei das S/A. In: FRANÇA, Erasmo Valladão Azevedo e Novaes; e ADAMEK, Marcelo Vieira von. Temas de Direito Empresarial e outros estudos em homenagem ao professor Luiz Gastão Paes de Barros Leães. São Paulo: Malheiros Editores, pp. 201-29, 2014.

Aquisição de Controle na Sociedade Anônima. Saraiva: São Paulo, 2013.

A importância do sistema de solução de conflitos para o direito societário: limite do instituto da arbitragem. In: YARSHELL, Flávio Luiz; PEREIRA, Guilherme Setoguti J. (Org.). Processo societário. São Paulo: Quartier Latin, p. 77-99, 2012.

. Desafios do Direito Societário Brasileiro na disciplina da companhia aberta: avaliação dos sistemas de controle diluído e concentrado. In: CASTRO, Rodrigo R. Monteiro de; e ARAgão, Leandro Santos de (orgs.). Direito societário - desafios atuais. São Paulo: Quartier Latin, v. 1, p. 120-157, 2009.

Empresa contemporânea e direito societário: poder de controle e grupos de sociedades. São Paulo: Juarez de Oliveira, 2002. 
121. MÜSSNICH, Francisco Antunes Maciel. O insider trading no Direito Brasileiro. São Paulo: Saraiva, 2017.

122. OIOLI, Erik Frederico. Oferta Pública de Aquisição do Controle de Companhias Abertas. São Paulo: Quartier Latin, 2010.

123. OLIVEIRA, Giovanna Bakaj. Insider Trading: questões relevantes. In: Relatório do Grupo de Direito Societário. Segundo Congresso Brasileiro de Direito Comercial. Grupo de Pesquisa da Universidade de Brasília - Unb, pp. 201-222, 2012.

124. PAREDES, Troy A. "Blinded by the Light: Information Overload and its Consequences for Securities Regulation". In: Washington Law Quarterly, vol. 81, n. ${ }^{\circ}$ 2, 2003, pp. 417-86.

125. PARENTE, Norma Jonssen. Aspectos Jurídicos do Insider Trading. CVM, junho de 1978, Rio de Janeiro: CVM em <http://www.cvm.gov.br/export/sites/cvm/menu/acesso_informacao/ serieshistoricas/estudos/anexos/Aspectos-Juridicos-do-insider-trading-NJP.pdf>， acessado em 08.01.2018).

126. PINTO, Frederico Lacerda da Costa. O novo regime dos crimes e contra-ordenação no Código dos Valores Mobiliários. Coimbra: Almedina, 2000.

127. PITTA, André Grünspun. O Regime de Informação das Companhias Abertas. São Paulo: Quartier Latin, 2013.

128. PRADO, Roberta Nioac. Oferta Pública de Ações Obrigatória nas S.A. - Tag Along. São Paulo: Quartier Latin, 2005.

129. PRADO, Viviane Muller (coord.). Insider Trading: dados e reflexões. Cadernos Direito GV. Seminário 38, vol. 7, n. 6, novembro 2010.

130. PRADO, Viviane Muller; e VILELA, Renato. "Radiografia de insider trading na CVM". Núcleo de estudos em Mercados e Investimentos - Direito GV, 2014 (disponível em <http://media.wix.com/ugd/66710c_e1b69e3f3f6843b092456f8551464531.pdf〉, acessado em 08.01.2018)

131. PRAdO, Viviane Muller; RAChMAN, Nora; e VILEla, Renato. Insider trading: normas, instituições e mecanismos de combate no Brasil. São Paulo: FGV Direito SP, 2016.

132. PROENÇA, José Marcelo Martins. Insider Trading - O primeiro caso de criminalização pela justiça brasileira. In: FRANÇA, Erasmo Valladão Azevedo e Novaes; e ADAMEK, Marcelo Vieira von. Temas de Direito Empresarial e outros estudos em homenagem ao professor Luiz Gastão Paes de Barros Leães. São Paulo: Malheiros, pp. 253-93, 2014. 
. Repúdio ao insider trading. In: SOUZA JÚNIOR, Francisco Satiro de (coord.).

Mercado de Capitais. Série GVlaw: Direito, Gestão e Prática. São Paulo: Saraiva, pp. 17-88, 2013.

Insider Trading: Regime Jurídico do Uso de Informações Privilegiadas no Mercado de Capitais. São Paulo: Quartier Latin, 2005.

133. Rachman, Nora. O Princípio do full disclosure no mercado de capitais. Dissertação de Mestrado sob orientação do Professor Newton Delucca apresentada à Faculdade de Direito da Universidade de São Paulo, 1999.

134. Rego, Anna Lygia Costa. Confiança e Investimento Estrangeiro: uma Análise do Ambiente Jurídico. Rio de Janeiro: Singular, 2013.

135. RIDER, Barry; ALEXANDER, Kern; e BAZLEY, Stuart. Market abuse and insider dealing. $3^{\mathrm{a}}$ ed., Bloomsbury Professional, 2016.

136. ROCHMAN, Ricardo R. e EID JR., William. Insiders conseguem retornos anormais? Estudos de eventos sobre as operações de insiders das empresas de governança corporativa diferenciada da Bovespa. In: VII Encontro Brasileiro de Finanças. São Paulo: Sociedade Brasileira de Finanças, 2007. V. 1, p. 1-16.

137. ROMANO, Roberta. ROMANO, Roberta. The need for competition in international securities regulation. In: Theoretical Inquiries in Law, vol. 2, n. ${ }^{\circ}$ 2, pp. 387-562, julho 2001.

Empowering investors: a market approach to securities regulation. In: Yale Law Journal, vol. 107, n. . 8, pp. 2.359-2.430, junho 1998.

138. Rose, Amanda M. The 'Reasonable Investor' of Federal Securities Law: Insights from Tort Law's 'Reasonable Person' \& Suggested Reforms (August 9, 2016). In: Journal of Corporation Law, vol. 43 (2017, a ser publicado); Vanderbilt Law Research Paper No. 17-05. Disponível em: https://ssrn.com/abstract=2840993 (acessado em 08.01.2018)

139. Salama, Bruno Meyerhof. 'O que é Direito e Economia?'. In: Timm, Luciano Benetti (org.). Direito e Economia. $2^{\mathrm{a}}$ ed. Porto Alegre: Livraria do Advogado, 2008.

140. SALLES, Marcos Paulo de Ameida. Aspectos da competência do CMN e da CVM no mercado de valores mobiliário. In: Revista de Direito Mercantil, vol. 108, pp. 101-

141. SAlomão Filho, Calixto. Informação completa, Direito Societário e mercado de capitais. In: O Novo Direito Societário. $4^{\mathrm{a}}$ ed., revista e ampliada, São Paulo: Malheiros Editores, pp. 177$187,2015$. 
. "Conflito de Interesses: oportunidade perdida" e "Conflito de interesses: novas esperanças". In: SALOMÃo FILHO, Calixto. O Novo Direito Societário. $4^{\mathrm{a}}$ ed., $2^{\mathrm{a}}$ tiragem, São Paulo: Malheiros Editores, 2015, p. 104-25. . "Reflexões sobre a disfunção dos mercados". In: FRANÇA, Erasmo Valladão Azevedo e Novaes; e ADAMEK, Marcelo Vieira Von. Temas de Direito Empresarial e outros estudos em homenagem ao professor Luiz Gastão Paes de Barros Leães. São Paulo: Malheiros Editores, 2014, pp. 294-315.

142. Salomão Neto, Eduardo. Direito bancário. $2^{\mathrm{a}}$ ed., São Paulo: Atlas, 2014.

143. Santos, Alexandre Pinheiro dos; OsóRIo, Fábio Medina; e Wellisch, Julya Sotto Mayor. Mercado de Capitais: Regime Sancionador. São Paulo: Saraiva, 2012.

144. Scala, Maíra Schweling. Estudo empírico dos termos de compromisso no âmbito da Comissão de Valores Mobiliários nos casos de insider trading. Professora Orientadora: Viviane Muller Prado. São Paulo: FGV, 2014.

145. SCAlZILli, João Pedro; e SPINELli, Luis Felipe. A racionalidade econômica do combate ao insider trading: assimetria de informação e dano ao mercado. In: Revista de Direito Mercantil Industrial, Econômico e Financeiro, v. 43, n. 147, São Paulo: Malheiros, p. 42-54, julho/setembro, 2007.

146. SchiPani, Cindy A.; e Seyhun, H. Nejat. Defining "Material, Nonpublic": What Should Constitute Illegal Insider Information?, 21 FORDHAM J. CORP. \& FIN. L. 327 (2016).

147. Schotland, Roy A. Unsafe at Any Price: a reply to Manne, Insider Trading and the Stock Market. In: Virginia Law Review, vol. 53, n. ${ }^{\circ}$ 7, pp. 1425-1478, 1967.

148. SEYHUN, H. Nejat. Insider Trading and the Effectiveness of Chinese Walls in Securities Firms. In: Journal of Law, Economics \& Policy, Vol. 4, Issue 2 (Spring 2008), pp. 369-408.

149. Silva, José Afonso da. Curso de Direito Constitucional Positivo. $21^{\mathrm{a}}$ ed. São Paulo: Malheiros, 2002.

150. SILVA, Mauricio Botelho. 'Insider trading' do acionista controlador. In: Revista de Direito Público, vol. 67, pp. 312-315, jul./set. 1983.

151. Simon, Herbert A. Models of Man: Social and Rational - Mathematical Essays on Rational Human Behavior on a Social Setting. New York: Wiley, 1957.

152. SPERCEL, Thiago A. Mercado de Capitais e Insider Trading. Dissertação de Mestrado sob a orientação do prof. Haroldo Malheiros Duclerc Verçosa, apresentada à Faculdade de Direito da Universidade de São Paulo, São Paulo, 2006. 
153. STRUDLER, Alan. Insider trading: a moral problem. In: Philosophy \& Public Policy Quarterly, vol. 29, n. ${ }^{o} 3 / 4$, verão/outuno de 2009, pp. 12-16.

154. TeIXEIRA, Egberto Lacerda; e GuERreiro, José Alexandre Tavares. Das Sociedades Anônimas no Direito Brasileiro. São Paulo: José Bushatsky, 1979.

155. TOLEDO, Paulo Fernando Campos Salles de. O Conselho de Administração na Sociedade Anônima. São Paulo: Atlas, 1997.

156. TRINDADE, Marcelo Fernandez. Mútuo de ações e insider trading. In: CASTRO, Rodrigo Rocha Monteiro de; WARDE JÚNIOR, Walfrido Jorge; e GUERREIRO, Carolina Dias Tavares (coords.). Direito empresarial e outros estudos em homenagem ao professor José Alexandre Tavares Guerreiro. São Paulo: Quartier Latin, pp. 517-535, 2013.

- Vedações à negociação de valores mobiliários por norma regulamentar: interpretação e legalidade. In: ADAMEK, Marcelo Vieira von (coord.). Temas de direito societário e empresarial contemporâneos: Liber Amicorum Prof. Dr. Erasmo Valladão Azevedo e Novaes França. São Paulo: Malheiros, p. 453-71, 2011.

O Papel da CVM e o mercado de capitais no Brasil. In: SADDI, Jairo (org.). Fusões e aquisições: aspectos jurídicos e econômicos. São Paulo: IOB, pp. 295-329, 2002.

157. TrubeK, David M.; VieIRA, Jorge Hilário Gouvêa; e SÁ, Paulo Fernandes de. Direito, planejamento e desenvolvimento do mercado de capitais brasileiro: 1965-1970. $2^{\mathrm{a}}$ ed., São Paulo: Saraiva, 2011.

158. TUCH, Andrew F. Financial conglomerates and information barriers. In: Journal of Corporation Law, Vol. 39, Issue 3 (Spring 2014), pp. 563-616.

159. TVERSKy, Amos; e KAHNEMAN, Daniel. Judgment under uncertainty: Heuristics and Biases. In: Science, Nova Série, vol. 185, n. ${ }^{\circ}$ 4157, setembro de 1974, pp. 1124-1131 (disponível em http://psiexp.ss.uci.edu/research/teaching/Tversky_Kahneman_1974.pdf, acessado em 08.01.2018).

160. Ventoruzzo, Marco. Do Market Abuse Rules Violate Human Rights? The Grande Stevens v. Italy Case (October 1, 2014). In: European Corporate Governance Institute (ECGI) - Law Working Paper No. 269/2014; Bocconi Legal Studies Research Paper No. 2517760. Nov 2014. Disponível em: https://ssrn.com/abstract=2517760 (acessado em 06.01.2017).

. Comparing insider trading in the United States and in the European Union: history and recent developments? MPILux Working Paper 5, 2014, p. 23, disponível em https://www.mpi.lu/fileadmin/mpi/medien/research/WPS_Marco_Ventoruzzo.pdf (acessado em 08.01.2018). 
161. VISCONTI, Rafael Ribeiro. Mercados globais, reguladores nacionais: a internacionalização do mercado de capitais e o caso do insider trader. In: Revista de Direito Mercantil, Industrial, Econômico e Financeiro, v.48, n. ${ }^{\circ}$ 151/152. São Paulo: RT, pp. 308-29, jan./dez. 2009.

162. VITTA, Heraldo Garcia. A Sanção no Direito Administrativo. São Paulo: Malheiros, 2003.

163. Wang, William K. S. The Contemporaneous Traders Who Can Sue an Inside Trader. In: Hastings Law Journal, vol. 38, n. ${ }^{\circ}$ 6, pp. 1175-94, Agosto 1987.

Trading on Material Nonpublic Information on Impersonal Stock Markets: Who Is Harmed, and Who Can Sue Whom under Sec Rule 10b-5. In: Southern California Law Review, vol. 54, n. ${ }^{\circ}$ 6, pp. 1217-22, setembro 1981.

164. WAng, William K. S.; e SteInBerg, Marc I. Insider Trading. 3a edição, Oxford: Oxford University Press, 2010.

165. YAZBEK, Otavio. A OPA por aumento de participação em um mercado em transformação. In: Rosseti, Maristela Abla; e PITTA, Andre Grünspun. Governança Corporativa: Avanços e Retrocessos. São Paulo, Quartier Latin, pp. 759-79, 2017.

Regulação do Mercado Financeiro e de Capitais. $3^{\mathrm{a}}$ ed., ampliada, São Paulo:

Campus, 2009. 


\section{ANEXO I - LISTA DE SIGLAS E ABREVIAÇÕES}

\begin{tabular}{|c|c|}
\hline ABRAPP & $\begin{array}{l}\text { Associação Brasileira das Entidades Fechadas de Previdência } \\
\text { Complementar }\end{array}$ \\
\hline ABRASCA & Associação Brasileira das Companhias Abertas \\
\hline ABVCAP & Associação Brasileira de Private Equity e Venture Capital \\
\hline $\mathrm{ADR}$ & American Depositary Receipts \\
\hline AMEC & Associação de Investidores no Mercado de Capitais \\
\hline AMF & Autorité des Marchés Financiers \\
\hline ANBIMA & $\begin{array}{l}\text { Associação Brasileira de Entidades dos Mercados Financeiro e de } \\
\text { Capitais }\end{array}$ \\
\hline APIMEC & $\begin{array}{l}\text { Associação dos Analistas e Profissionais de Investimento do Mercado de } \\
\text { Capitais }\end{array}$ \\
\hline BACEN & Banco Central do Brasil \\
\hline BDR & Brazilian Depository Receipts \\
\hline BM\&FBOVESPA & BM\&FBOVESPA S.A. - Bolsa de Valores, Mercadorias e Futuros \\
\hline BNDES & Banco Nacional de Desenvolvimento Econômico e Social \\
\hline BRAIN & BRAiN - Brasil Investimentos \& Negócios \\
\hline BSM & BM\&FBOVESPA Supervisão de Mercados \\
\hline CETIP & CETIP S.A. - Mercados Organizados \\
\hline $\mathrm{CF} / 88$ & $\begin{array}{l}\text { Constituição da República Federativa do Brasil de 1988, conforme } \\
\text { alterada }\end{array}$ \\
\hline CFA Institute & Chartered Financial Analyst Institute \\
\hline $\mathrm{CMN}$ & Conselho Monetário Nacional \\
\hline COAF & Conselho de Controle das Atividades Financeiras \\
\hline CONSOB & Commissione Nazionale per le Società e la Borsa \\
\hline COPOM & Comitê de Política Monetária \\
\hline COSRA & Council of Securities Regulators of the Americas \\
\hline CPMF & $\begin{array}{l}\text { Contribuição Provisória sobre Movimentações ou Transmissão de } \\
\text { Valores e de Créditos e Direitos de Natureza Financeira }\end{array}$ \\
\hline CRSFN & Conselho de Recursos do Sistema Financeiro Nacional \\
\hline DFP & Demonstrações Financeiras Padronizadas \\
\hline DOJ & United States Department of Justice \\
\hline ESMA & European Securities and Markets Authority \\
\hline FATF & Financial Action Task Force \\
\hline FR & Formulário de Referência \\
\hline FCA & United Kingdom Financial Conduct Authority \\
\hline GAFISUD & Grupo de Acción Financiera de Sudamérica \\
\hline IAN & Informações Anuais \\
\hline
\end{tabular}


IASB

IBGC

IBMEC

IBRI

IFRS

IIMV

IOSCO

Instrução CVM n. ${ }^{\circ}$ 8/79

Instrução CVM n. ${ }^{\circ}$ 10/80

Instrução CVM n. ${ }^{\circ}$ 306/99

Instrução CVM n. ${ }^{\circ}$ 358/2002

Instrução CVM n. ${ }^{\circ}$ 361/2002

Instrução CVM n. ${ }^{\circ}$ 400/2003

Instrução CVM n. ${ }^{\circ}$ 480/2009

Instrução CVM n. ${ }^{\circ}$ 483/2010

Instrução CVM n. ${ }^{\circ}$ 521/2012

Instrução CVM n. ${ }^{\circ}$ 530/2012

IPO

Lei Anti-Corrupção

Lei das S/A

Lei de Improbidade

Administrativa

Lei da Reforma Bancária

Lei de Responsabilidade Fiscal

Lei do Mercado de Capitais

Lei do Mercado de Valores Mobiliários

Lei Orgânica do Ministério Público

MAR (EU)

MP784/2017

NASDAQ

NYSE

OCDE

OICV

OPA

ORTN
International Accounting Standards Board (Comitê de Normas Internacionais de Contabilidade)

Instituto Brasileiro de Governança Corporativa

Instituto Brasileiro de Mercado de Capitais

Instituto Brasileiro de Relações com Investidores

International Financial Reporting Standards (Normas Internacionais de Contabilidade)

Instituto Iberoamericano de Mercado de Valores

International Organization of Securities Commissions

Instrução CVM n. ${ }^{\circ}$ 8, de 8 de outubro de 1979, conforme modificada

Instrução CVM n. ${ }^{\circ}$ 10, de 14 de fevereiro de 1980, conforme modificada

Instrução CVM n. ${ }^{\circ}$ 306, de 5 de maio de 1999, conforme modificada

Instrução CVM n. ${ }^{\circ} 358$, de 3 de janeiro de 2002, conforme modificada

Instrução CVM n. ${ }^{\circ}$ 361, de 5 de março de 2002, conforme modificada

Instrução CVM n. ${ }^{\circ} 400$, de 29 de dezembro de 2003, conforme modificada

Instrução CVM n. ${ }^{\circ}$ 480, de 7 de dezembro de 2009, conforme modificada

Instrução CVM n. ${ }^{\circ} 483$, de 6 de julho de 2010, conforme modificada

Instrução CVM n. ${ }^{\circ}$ 521, de 25 de abril de 2012

Instrução CVM n. ${ }^{\circ}$ 530, de 22 de novembro de 2012

Initial Public Offering (oferta pública inicial)

Lei n. ${ }^{\circ} 12.846$, de 1 de agosto de 2013

Lei n. ${ }^{\circ} 6.404$, de 15 de dezembro de 1976, conforme alterada

Lei n. ${ }^{\circ} 8.429$, de 2 de junho de 1992, conforme alterada

Lei n. ${ }^{\circ}$ 4.595, de 31 de dezembro de 1964, conforme alterada

Lei Complementar n. ${ }^{\circ} 101$, de 04 de maio de 2000, conforme alterada

Lei n. ${ }^{\circ} 4.728$, de 14 de julho de 1965, conforme alterada

Lei n. ${ }^{\circ}$ 6.385, de 7 de dezembro de 1976, conforme alterada

Lei n. ${ }^{\circ} 8.625$, de 12 de fevereiro de 1993, conforme alterada

Market Abuse Regulation (European Union) ou Regulation (EU) n. ${ }^{\circ}$ 596/2014 of the European Parliament and of the Council

Medida Provisória n. ${ }^{\text {7 }}$ 784, de 07 de junho de 2017

National Association of Securities Dealers Automated Quotations

New York Stock Exchange

Organização para a Cooperação e Desenvolvimento Econômico

Organização Internacional de Comissões de Valores

Oferta pública de aquisição de ações

Obrigação Reajustável do Tesouro Nacional 
SEC

SFN

STOCK Act

SUMOC
Securities and Exchange Commission

Sistema Financeiro Nacional

Stop Trading on Congressional Knowledge Act

Superintendência da Moeda e do Crédito

*** 


\section{ANEXO II - QUADRO SINÓTICO}

\begin{tabular}{|c|c|c|c|c|c|}
\hline Norma & Sujeito & Ação & Informação & Acesso ou Ciência & Elemento volitivo \\
\hline LSA, art. $155, \S 1^{\circ}$ & insiders primários & $\begin{array}{l}\text { valer-se da informação na } \\
\text { compra ou venda de } \\
\text { valores mobiliários. }\end{array}$ & $\begin{array}{l}\text { informação que ainda não tenha } \\
\text { sido divulgada para conhecimento } \\
\text { do mercado, e capaz de influir de } \\
\text { modo ponderável }\end{array}$ & $\begin{array}{l}\text { obtida em razão do } \\
\text { cargo }\end{array}$ & $\begin{array}{l}\text { para obter, para si } \\
\text { ou para outrem, } \\
\text { vantagem }\end{array}$ \\
\hline LSA, art. $155, \S 4^{\circ}$ & qualquer pessoa & $\begin{array}{c}\text { utilizar a informação no } \\
\text { mercado de valores } \\
\text { mobiliários }\end{array}$ & $\begin{array}{c}\text { informação relevante ainda não } \\
\text { divulgada }\end{array}$ & $\begin{array}{l}\text { que a ela tenha tido } \\
\text { acesso }\end{array}$ & $\begin{array}{c}\text { finalidade de } \\
\text { auferir vantagem, } \\
\text { para si ou para } \\
\text { outrem } \\
\end{array}$ \\
\hline $\begin{array}{l}\text { ICVM 358, art. } \\
13\end{array}$ & insiders primários & $\begin{array}{l}\text { negociar com valores } \\
\text { mobiliários }\end{array}$ & $\begin{array}{c}\text { informação relativa ao ato ou fato } \\
\text { relevante ocorrido nos negócios } \\
\text { da companhia ainda não } \\
\text { divulgada }\end{array}$ & tenha conhecimento & \\
\hline $\begin{array}{c}\text { ICVM } 358, \text { art. } \\
13, \S 1^{\circ}\end{array}$ & $\begin{array}{l}\text { quem quer que tenha } \\
\text { conhecimento, em } \\
\text { especial insiders } \\
\text { temporários } \\
\end{array}$ & $\begin{array}{l}\text { negociar com valores } \\
\text { mobiliários }\end{array}$ & $\begin{array}{c}\text { informação referente a ato ou fato } \\
\text { relevante }\end{array}$ & tenha conhecimento & $\begin{array}{l}\text { saber se tratar de } \\
\text { informação ainda } \\
\text { não divulgada }\end{array}$ \\
\hline LMVM, art. 27-D & qualquer pessoa & $\begin{array}{l}\text { utilizar a informação para } \\
\text { negociar, em nome } \\
\text { próprio ou de terceiros, de } \\
\text { valores mobiliários }\end{array}$ & $\begin{array}{c}\text { informação relevante ainda não } \\
\text { divulgada ao mercado }\end{array}$ & tenha conhecimento & $\begin{array}{c}\text { seja capaz de } \\
\text { propiciar, para si ou } \\
\text { para outrem, } \\
\text { vantagem indevida, }\end{array}$ \\
\hline $\begin{array}{l}\text { LMVM, art. 27- } \\
\qquad \mathrm{D}, \S 1^{\circ}\end{array}$ & $\begin{array}{l}\text { insiders primários e } \\
\text { temporários }\end{array}$ & repassar a informação & $\begin{array}{c}\text { informação sigilosa relativa a fato } \\
\text { relevante }\end{array}$ & $\begin{array}{c}\text { a que tenha tido } \\
\text { acesso em razão de } \\
\text { cargo }\end{array}$ & \\
\hline
\end{tabular}

Obs: A comparação acima extrai trechos de cada disposição para comparar os textos legais e normativos 